\title{
Violência homicida no nordeste brasileiro: uma refutação às explicações baseadas na desigualdade e na pobreza
}

José Maria Nóbrega Jr e Jorge Zaverucha

\section{(2) OpenEdition \\ Journals}

Edição electrónica

URL: http://journals.openedition.org/aa/895

DOI: $10.4000 /$ aa. 895

ISSN: 2357-738X

Editora

Programa de Pós-Graduação em Antropologia Social (UnB)

Edição impressa

Data de publição: 1 dezembro 2010

Paginação: 53-87

ISSN: 0102-4302

Refêrencia eletrónica

José Maria Nóbrega Jr e Jorge Zaverucha, «Violência homicida no nordeste brasileiro: uma refutação às explicações baseadas na desigualdade e na pobreza», Anuário Antropológico [Online], v.35 n.2 I 2010, posto online no dia 15 outubro 2015, consultado o 28 abril 2021. URL: http:// journals.openedition.org/aa/895 ; DOl: https://doi.org/10.4000/aa.895

\section{(c) $($ ) $(3)$}

Anuário Antropológico is licensed under a Creative Commons Atribuição-Uso Não-Comercial-Proibição de realização de Obras Derivadas 4.0 International. 


\title{
Violência homicida no nordeste brasileiro: uma refutação às explicações baseadas na desigualdade e na pobreza
}

\author{
José Maria Nóbrega Jr \\ Faculdade Maurício de Nassau \\ Jorge Zaverucha \\ Departamento de Ciência Política/UFPE
}

\section{Introdução}

Boa parte da literatura nas ciências sociais aponta para a relação entre violência homicida $^{1}$ e desigualdade/pobreza (Nóbrega Jr., Zaverucha \& Rocha, 2009). Esta literatura foca nas regiões Sul e Sudeste como base para fundamentar tal relação no Brasil nos últimos anos. O Nordeste, portanto, é negligenciado na maioria das análises sobre o fenômeno da violência. Outro ponto importante é a quase ausência do uso de instrumentos da ciência política na análise do fenômeno homicídio nos estudos acadêmicos. A sociologia e a antropologia são as ciências dominantes nesta área.

Neste artigo buscamos respostas, à luz da ciência política, para o fenômeno do crescente número de homicídios no Nordeste nos últimos anos. Procuraremos demonstrar que a desigualdade e a pobreza não têm relação de causalidade com os homicídios (variável dependente de nosso estudo). ${ }^{2}$

Para tanto, abordamos sumariamente algumas obras que atrelam os homicídios a questões estruturais (macrovariatas socioeconômicas). Em seguida, focamos a dinâmica das mortes violentas por homicídios - baseados no banco de dados do SIM/DATASUS e nos dados da SDS-PE - suas relações causais com variáveis categóricas (gênero, raça/etnia etc.), variáveis numéricas (faixa etária) e variáveis de caráter socioeconômico (também chamadas macrovariatas). Tudo isso no intuito de explicar o fenômeno dos homicídios na região mais violenta do Brasil: a região Nordeste, e como a desigualdade e a pobreza não têm relação causal com o controle dos homicídios.

Literatura nacional sobre desigualdade e pobreza e sua relação com a violência homicida

Como afirmamos acima, na literatura nacional que se detém nas análises sobre a violência em geral e os homicídios em particular há a tendência a estabelecer 
uma relação causal ou correlação entre este fenômeno e a desigualdade social e de renda e a pobreza como fatores causais determinantes (Nóbrega Jr., Zaverucha \& Rocha, 2009).

A desigualdade social e de renda e a pobreza geralmente são medidas por indicadores socioeconômicos. O indicador de Gini, a renda domiciliar per capita, o percentual de domicílios pobres, as taxas de analfabetismo, o nível de escolaridade, o Produto Interno Bruto (PIB), o nível de consumo de energia elétrica, o Índice de Desenvolvimento Humano (IDH) etc. são todas elas variáveis independentes utilizadas nos modelos de correlação/associação entre desigualdade/pobreza e violência. Esta, geralmente, medida pelas taxas ou pelos números absolutos de homicídios, ou pelo quantitativo de crimes contra o patrimônio, como os roubos e os furtos. Contudo, os homicídios costumam aparecer como proxy $y^{3}$ para a violência.

Sabemos que a definição da desigualdade social e / ou de renda e da pobreza passa por um viés antropossociológico e é por demais subjetiva. No entanto, nós aqui percebemos que os indicadores socioeconômicos disponíveis são importantes para a definição e a posterior mensuração do impacto real das variáveis independentes em relação aos homicídios.

Outro ponto importante que deve ser destacado está relacionado à questão dos estudos sobre homicídios/violência no Brasil nas regiões Sul/Sudeste. Muitos trabalhos levam em consideração o aspecto nacional, tendo como testes o nível regional. A maioria dos trabalhos atenta para o problema da violência nessas regiões e negligencia a região Nordeste. Mostraremos que não há como generalizar as causas dos homicídios em uma ou duas regiões. Dessa forma, passa a ser fundamental a análise pontual das reais causas regionais.

Alguns trabalhos se destacam na relação entre homicídios, como proxy de violência, e a desigualdade de renda e social e a pobreza. Alguns ensaios levaram a conclusões interessantes, mas com graves limitações empíricas. Zaluar (1985), por exemplo, em um importante estudo etnográfico, afirmou existir uma relação entre pobreza e violência no Rio de Janeiro. Pezzin (1986) encontrou, na região metropolitana de São Paulo, uma correlação positiva relevante entre urbanização, pobreza e desemprego no que diz respeito a crimes contra o patrimônio. Estas mesmas variáveis, todavia, não se correlacionaram significativamente com os crimes contra a pessoa.

Em alguns trabalhos o desenvolvimento econômico foi causa do crescimento da violência, sobretudo contra o patrimônio. Por exemplo, Beato e Reis (2000) concluíram que o desenvolvimento social e econômico motiva o crescimento da violência, especialmente os crimes contra o patrimônio. Além disso, há a influência na ação criminosa dos contextos de oportunidades (alvos potenciais e ausência ou fragilidade de mecanismos de controle e vigilância). 
A teoria das oportunidades representada empiricamente no estudo aponta que em municípios mais desenvolvidos há: a) mais riquezas disponíveis; b) maior número de ofensores motivados; e c) mecanismos frágeis de coerção. Os modelos estatísticos citados pelos autores relacionam variáveis socioeconômicas às taxas de criminalidade. Por outro lado, os mesmos autores demonstraram que a desigualdade e a pobreza pouco influenciam o crime violento. Os modelos de regressão e os de correlação mostraram baixa significância de relação entre pobreza/ desigualdade e criminalidade violenta. Esta foi definida como os crimes violentos contra a pessoa, crimes violentos contra o patrimônio, roubo, roubo à mão armada e roubo de veículo e assalto a veículos. Os indicadores de pobreza/desigualdade foram o Coeficiente de Gini e a percentagem de chefes de família com menos de um salário mínimo. Os modelos de regressão apresentados não mostraram relação significante entre pobreza/desigualdade e violência (Beato e Reis, 2000:389, 390).

No mesmo trabalho, estes autores apontaram uma expressiva significância entre as taxas de incidência de drogas e os homicídios, maior que as relações encontradas entre as variáveis socioeconômicas e a violência homicida. Os resultados principais do trabalho de Beato e Reis (2000) mostram que o crime violento contra o patrimônio tem maior relação com as variáveis socioeconômicas, e o crime violento contra a vida (homicídios) apresenta forte ligação com o consumo de drogas e com a ineficácia do aparato coercitivo (Nóbrega Jr., 2010:53, 54).

Andrade e Lisboa (2000) estudaram os homicídios em três importantes estados brasileiros - Minas Gerais, Rio de Janeiro e São Paulo - que foram avaliados no período de 1981 a 1997. O objetivo central dos autores foi analisar a evolução da taxa de homicídios nestes estados. Particularmente, o trabalho verificou a existência de relação entre a evolução dos homicídios e as variáveis econômicas, como salário real, desemprego, coeficiente de Gini etc.

A pesquisa destes autores apresentou três resultados básicos:

1. A organização dos dados segundo as coortes ${ }^{4}$ dos indivíduos pareceu ser um tratamento adequado para o entendimento dos ciclos de violência. A probabilidade de morte homicida é crescente com a idade, atingindo o pico na faixa entre 20 e 25 anos.

2. Indivíduos mais jovens se moveriam das atividades legais para as ilegais com maior facilidade do que os mais velhos. Esse movimento seria influenciado pelas variáveis econômicas. Os jovens entre 15 e 19 anos estão mais inclinados a atividades ilegais.

3. A diferença entre as taxas de homicídios no Rio de Janeiro e São Paulo é significativamente reduzida quando essas taxas são controladas pelo efeito inércia ${ }^{5}$ e pelas variáveis econômicas. Para a maioria das idades, a diferença não-controlada das taxas de homicídio é duas vezes superior no Rio de Janeiro em relação a São Paulo. 
Mendonça (2000) afirma que o indivíduo possui um consumo referencial imposto pelos padrões da sociedade. A partir do momento em que o agente não tem o consumo satisfeito, é gerada uma insatisfação que o leva à prática criminosa. Tendo como base a análise elaborada num contexto de maximização inter temporal, é possível demonstrar que o retorno exigido pelo agente para levar à efetivação da atividade ilícita pode ser reduzido por uma quantidade diretamente relacionada com o seu grau de insatisfação (Becker, 1968).

O autor seguiu uma metodologia para testar a desigualdade social em relação à criminalidade em diversas unidades da federação, considerando como base metodológica dados de painel. Tal mecanismo metodológico tem a vantagem de conjugar informação cross-section com séries de tempo. O período analisado foi de dez anos, 1985 a 1995. O método escolhido por Mendonça permitiu obter estimadores que levaram em conta a heterogeneidade existente entre os estados. Para ele, a desigualdade socioeconômica potencializa a criminalidade desde que exista o reconhecimento de que o agente possua um nível de consumo de referência, imposto a ele de forma exógena.

No caso de São Paulo e Rio de Janeiro, a proximidade e a convivência entre grupos sociais distintos e a disseminação de um padrão de consumo e de padrões sociais de referência via meios de comunicação estimulariam a criminalidade. A insatisfação gerada pela exclusão formal daquele mercado consumidor reduz a utilidade e faz com que o indivíduo perceba sua renda como menor, inibindo, em consequência, o valor descontado da sua utilidade futura, e assim contribuindo como mais um elemento de motivação para que o agente entre no mercado da criminalidade, ou seja, quando o indivíduo se depara com uma renda maior no mercado informal, ele opta por praticar o delito.

Algumas variáveis foram utilizadas como proxies no modelo econométrico para avaliar o retorno esperado pelo agente na atividade ilícita e até que ponto a desigualdade socioeconômica potencializa a criminalidade. A renda média das famílias por estado e o PIB per capita foram colocados como proxy de avaliação do retorno econômico esperado. Quanto ao custo de ingresso na criminalidade, foi empregada a variável de taxa de urbanização. ${ }^{6} \mathrm{O}$ índice de Gini foi usado como proxy para desigualdade de renda. A variável dependente relacionada com a criminalidade foi o número de homicídios intencionais. O Gini e a urbanização tiveram ligação positiva com o crescimento da criminalidade homicida, já as variáveis renda e desemprego não mostraram ser significativas (Nóbrega Jr., 2010:58).

Cerqueira, Lobão e Carvalho (2007) defendem a hipótese da ligação dos homicídios com fatores estruturais. Destacam o crescimento da população urbana entre a década de 70 e o ano 2000, apontando o efeito deste crescimento, 86 milhões de pessoas, no aumento da demanda por políticas públicas em diversas áreas. Mas foram nas macrovariatas ${ }^{7}$ que foram executados os testes estatísticos mais robustos. 
Baseados numa literatura que reforça teoricamente a relação de causalidade entre a desigualdade socioeconômica e a criminalidade, generalizam sua análise tendo como base dois estados do sudeste: Rio de Janeiro e São Paulo. A abordagem teórica foi confirmada pelo modelo estatístico. Os homicídios foram explicados pelo contingente populacional, pela desigualdade da renda, pela renda domiciliar per capita e pelas despesas com segurança pública.

Nos modelos apresentados para o Rio de Janeiro e São Paulo para os anos de 2002 a 2006, os autores verificaram que a evolução da renda, da desigualdade e dos gastos reais com segurança pública, o aumento da renda per capita em 4\% a cada ano e o aumento das despesas em segurança pública em $10 \%$ reais a cada ano tiveram efeito positivo nas taxas de homicídios. Assim, o incremento dessas variáveis fez crescer os homicídios quando elas foram testadas em particular. A diminuição da desigualdade em $2 \%$ ao ano e as variáveis descritas acima de forma agregada demonstraram efeito negativo nos homicídios, ou seja, foram importantes para a redução da criminalidade (Cerqueira; Lobão \& Carvalho, 2007:155, 156).

Dos resultados empíricos, os autores concluíram que não há como equacionar a criminalidade na região estudada se não forem superados os grandes problemas socioeconômicos, e que as políticas baseadas simplesmente em aportes de recursos financeiros à polícia estão fadadas a resultados frágeis, a menos que se repense a estrutura de segurança vigente no Brasil (ibidem:156, 157).

Barata e Ribeiro (2000) chegaram a conclusões inversas quanto a desenvolvimento, desigualdade e pobreza e as suas relações com os homicídios como proxy para a violência. Os autores distinguiram a importância da literatura nacional e internacional que trata do tema da violência ligando-a à questão da pobreza e dos desajustes sociais. Destacaram, com forte influência marxista, que alguns estudos mostram que há três condições que promovem altas taxas de delinquência: a pobreza, a heterogeneidade social e a mobilidade (Barata \& Ribeiro, 2000:119).

Não obstante, os autores observaram que, quando aplicados métodos quantitativos nas análises sobre o fenômeno em destaque, os resultados empíricos apresentam relações que revelam uma surpresa: riqueza e desenvolvimento econômico podem levar a crescimento nas taxas de homicídios. ${ }^{8}$ Citando Lester (1996), apontaram que o estudo deste autor demonstrou uma conexão positiva entre o produto interno bruto (PIB) per capita e as taxas de homicídios, numa amostra que relacionava mais de 44 países. Barata e Ribeiro (2000), com isto, afirmaram ser mais importante avaliar o impacto da desigualdade social, da urbanização e dos crescimentos populacionais do que levar como variável independente a pobreza, que teria uma relação direta com questões meramente econômicas. De toda forma, neste estudo, consideraram variáveis tidas como proxies para pobreza, como o coeficiente de Gini e a renda familiar. 
Aqui, iremos abordar a questão da desigualdade e da pobreza quanto aos homicídios no nordeste brasileiro, levando em consideração algumas dessas variáveis encontradas na literatura e apontando para uma relação inversa entre tais variáveis e os homicídios.

\section{Dinâmica dos homicídios na região Nordeste brasileira}

A região Nordeste brasileira vem apresentando crescimento constante de mortes por agressão desde 1996. De 1996, com 8.119 mortes, a 2008, com 16.729 mortes, o incremento percentual nos números absolutos ultrapassou os 100\% nesta série histórica. Afora os anos 1998, 1999 e 2004, todos os outros apresentaram crescimento. ${ }^{9}$

As regiões Norte, Nordeste e Centro-Oeste apresentam taxas superiores à nacional. A região Sul tem hoje uma taxa de 24 homicídios por 100 mil habitantes (hpcmh) e a Sudeste, 20,5 por 100 mil. O Brasil, acrescentando o Distrito Federal $(31,6)$, tem a taxa de 25 por 100 mil habitantes; a região Sul, com tendência crescente; a Sudeste, com taxas menores que a nacional (tabela 1).

\section{Tabela 1.Taxas de homicídios nas regiões brasileiras - 2008}

\begin{tabular}{|l|l|}
\hline Região Norte & 30,9 \\
\hline Região Nordeste & 31,5 \\
\hline Região Sudeste & 20,5 \\
\hline Região Sul & 24,0 \\
\hline Região Centro-Oeste & 30,3 \\
\hline Distrito Federal & 31,6 \\
\hline Brasil & 25,6 \\
\hline
\end{tabular}

Fonte: SIM/DATASUS. Taxas Nóbrega Jr. (2010)

O que difere, de forma destacada, a região Sudeste da Nordeste é que a primeira vem apresentando decréscimo contínuo de mortes por agressão nos últimos seis anos da série histórica 1980 a 2008. Todas as regiões, com exceção da Sudeste, apresentam tendência de crescimento na série analisada. Contudo, a região Nordeste tem maior impacto percentual no crescimento agregado (cf. gráfico 1).

As taxas apontam bem o incremento das mortes por agressão levando em consideração o crescimento da população. Observa-se que as taxas, no início da década de 80 no Nordeste, eram menores que a admitida pela Organização Mundial de Saúde (OMS), ou seja, menos de 10 homicídios por cada grupo de 100 mil habitantes. O gráfico acima demonstra a tendência de crescimento das taxas nos anos posteriores. 
No final da série histórica a taxa é de 31,5 homicídios por 100 mil habitantes. A região Sudeste segue uma trajetória de fortalecimento das taxas até o ano 2000. A partir daí, a tendência é de queda nas taxas. No início da série histórica o registro é de 15,2 hpcmh, alcançando 36,5 hpcmh em 2000. Não obstante, a redução contínua de suas taxas é visível, chegando ao final da série histórica em destaque com 20,5 hpcmh.

\section{Gráfico 1.Taxas de mortes por agressão - Nordeste e Sudeste 1980 a 2008}

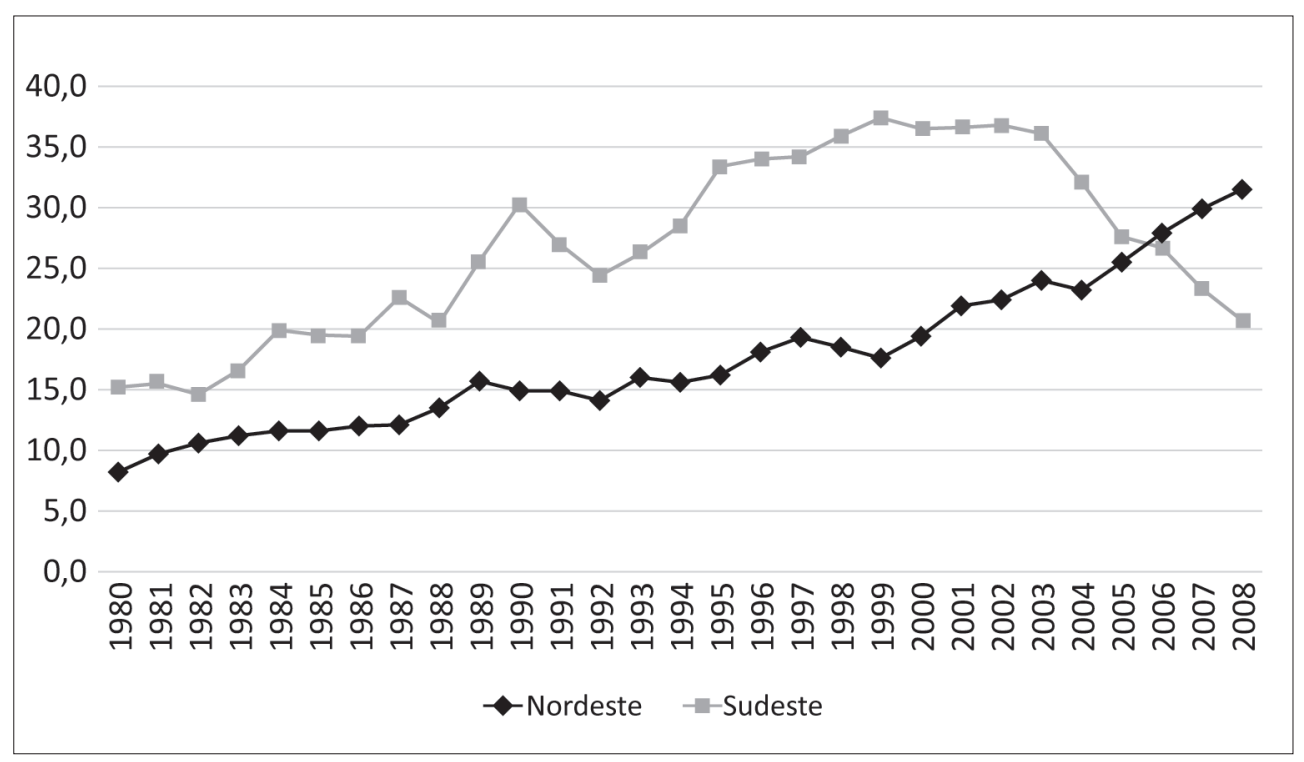

Fonte: SIM/MS. Cálculo das Taxas Nóbrega Jr. (2009)

Apesar de na região Nordeste o crescimento ser a regra, Pernambuco, Alagoas e Bahia destacam-se em relação aos outros estados da região. O Nordeste vem apresentando o maior impacto nas mortes deste tipo no país, e estes três estados têm sido responsáveis por praticamente $2 / 3$ dos homicídios.

A Bahia apresenta um nível de crescimento bastante acentuado na série histórica, sobretudo nos quatro últimos anos. Desde 2000, com períodos de queda constante entre 1997 e 1999, a dinâmica dos assassinatos vem tendo permanente impacto positivo. De 1999, com 913 homicídios, até 2008, com 4.709, o impacto percentual nos números absolutos foi impressionante: $430 \%$ de crescimento.

Alagoas é outro estado preocupante. Com 1.878 assassinatos em 2008, contribui com quase $12 \%$ das mortes por agressão no Nordeste. Entre 2004 e 2008 foram 843 mortes a mais no cômputo geral dos homicídios - quase 100\% de aumento em quatro anos. 
Pernambuco é responsável por quase 30\% das mortes por agressão de toda a região. Desde 2004 os indicadores mostram crescimento constante neste estado: em 2004, com 4.174 mortes deste tipo, e em 2007, com 4.556 assassinatos, o que corresponde a um crescimento percentual de $9 \%$ nos números absolutos. Em 2008, depois de três anos de crescimento, houve queda de 4,6\%, com 211 mortes a menos em relação ao ano de 2007.

\section{Gráfico 2. Mortes por agressão em números absolutos - 1996 a 2008 estados nordestinos}

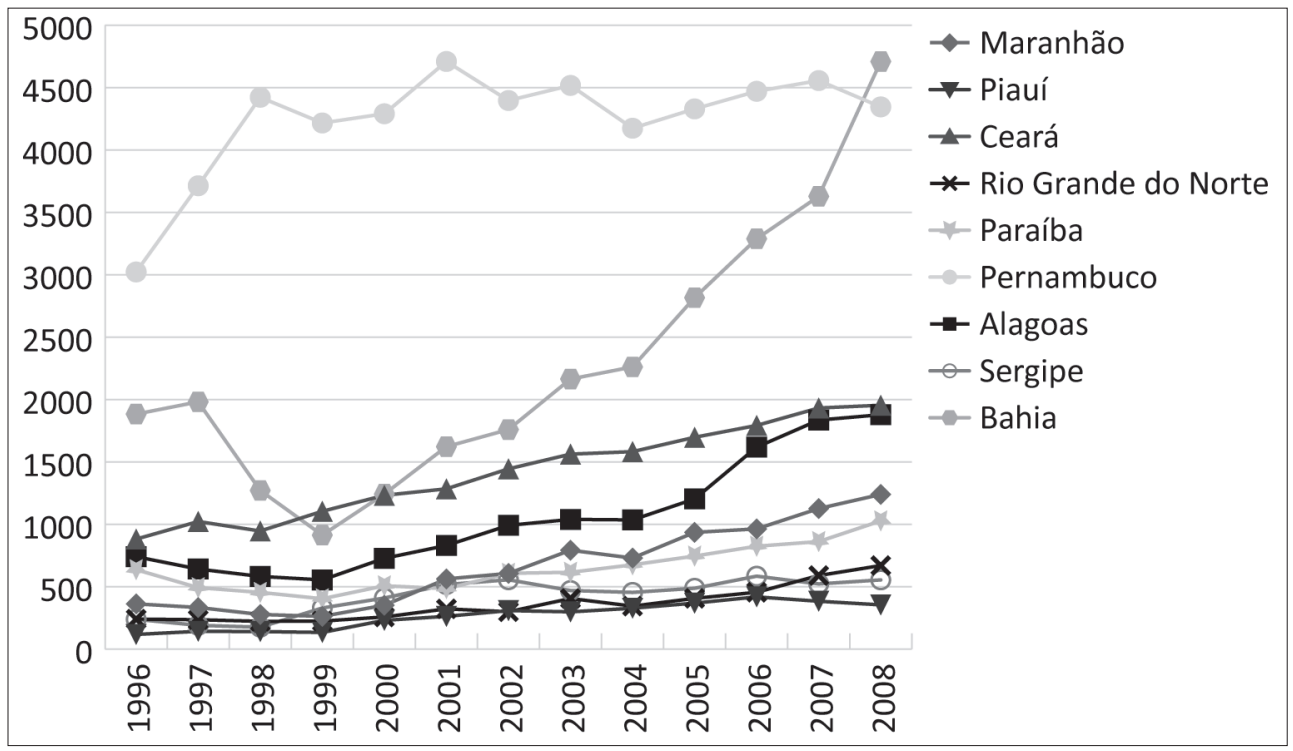

Fonte: SIM/DATASUS (2009)

No Ceará os números de homicídio cresceram significativamente. Em 1996, os números absolutos evoluíram de forma continuada até o final da série histórica, em 2008, praticamente dobrando os números. Em 1996, com 881 mortes e, em 2008, com 1.954 assassinatos. O Ceará está há dez anos sem redução em suas taxas, um crescimento aproximado de 122\% na série histórica.

O Maranhão é outro estado que apresentou crescimento significativo nos números absolutos de homicídios. Em 1996 ocorreram 362 assassinatos, com poucos anos de retração, até 1.239 mortes deste tipo em 2008, ou seja, houve um incremento percentual na ordem de $242 \%$.

Houve um crescimento significativo de $203 \%$ na série histórica do Piauí. Em 1996 foram computados 117 assassinatos, evoluindo até o ano de 2008 com mais 237 pessoas vitimadas, ou seja, 354 homicídios. 
O Rio Grande do Norte teve um aumento expressivo de 178\%. Em 1996, foram registrados 240 assassinatos, num crescendo até o ano de 2008 de mais de 429 pessoas vitimadas, isto é, 669 homicídios.

Sergipe apresentou crescimento na ordem de 134\% nos números absolutos de homicídios na mesma série histórica. Em 1996 foram 238 pessoas vitimadas e, em 2008, houve 554 homicídios, ou seja, 792 homicídios.

A Paraíba também é outro estado com aumento significativo nas taxas. Em 1996, ocorreram 636 assassinatos em relação a 2008, que computou 1.027 homicídios, tendo incremento percentual na ordem dos $60 \%$.

Depois de contemplados os dados agregados para a região Nordeste, eles serão desagregados para o número de homicídios no estado de Pernambuco. Além da preocupação em analisar a dinâmica quantitativa dos homicídios neste estado, outras variáveis (independentes) serão estudadas em relação aos homicídios, sendo elas: faixa etária, gênero, raça/etnia, escolaridade e estado civil. Estas microvariáveis categóricas são importantes, pois predizem muitas questões fundamentais sobre os grupos mais vitimados pelas mortes por agressão, a análise demonstrando a relação real com a variável dependente (homicídios). Estudaremos o impacto de cada uma destas variáveis nas mortes por agressão (homicídios), avaliando a relação de causalidade entre elas.

\section{Os homicídios em Pernambuco: a dinâmica das mortes letais intencionais}

O estado de Pernambuco tem apresentado impacto significativo nos indicadores de violência no Brasil nos últimos 11 anos. Está entre os primeiros do ranking nacional, com altas taxas de homicídios. Desde 1998 vem tendo uma média de mais de 4.400 mortes por agressão computadas nos dois bancos de dados disponíveis, o SIM e o INFOPOL/SDS (PE). Aqui serão desenvolvidas a dinâmica e a análise das variáveis independentes (faixa etária, arma de fogo etc.) de mortes por agressão (homicídios) para o estado de Pernambuco, tendo como referência empírica o SIM. ${ }^{10}$

Entre 1990 e 1993, há queda nas taxas de homicídios em Pernambuco. Em 1994, a taxa sai do patamar de 37,6 do ano anterior e cai para 36,4 homicídios por 100 mil habitantes pernambucanos. O período crítico engloba os anos de 1994 a 1998. Pernambuco apresenta uma "explosão" no índice de homicídios por $100 \mathrm{mil}$ habitantes. As taxas saltam de 34,9 para 58,9 entre os anos de 1994 e 1998, quase dobrando as taxas de homicídios no estado. De 1998 a 2008 o estado de Pernambuco apresenta uma tendência à estabilidade, como pode ser visto no gráfico acima. Não obstante, a média de mais de 4.400 mortes, com as taxas oscilando entre os 50 e 60 por 100 mil nos últimos dez anos (98 a 08), é preocupante.

Sabe-se que a maioria dessas mortes tem fortíssima relação com a disponibilidade de armas de fogo (Soares, 2008). Para tanto, é de fundamental importância avaliar o impacto desta variável nas mortes por agressão. 


\section{Gráfico 3.Taxas das mortes por agressão em Pernambuco 1990 a 2008 *}

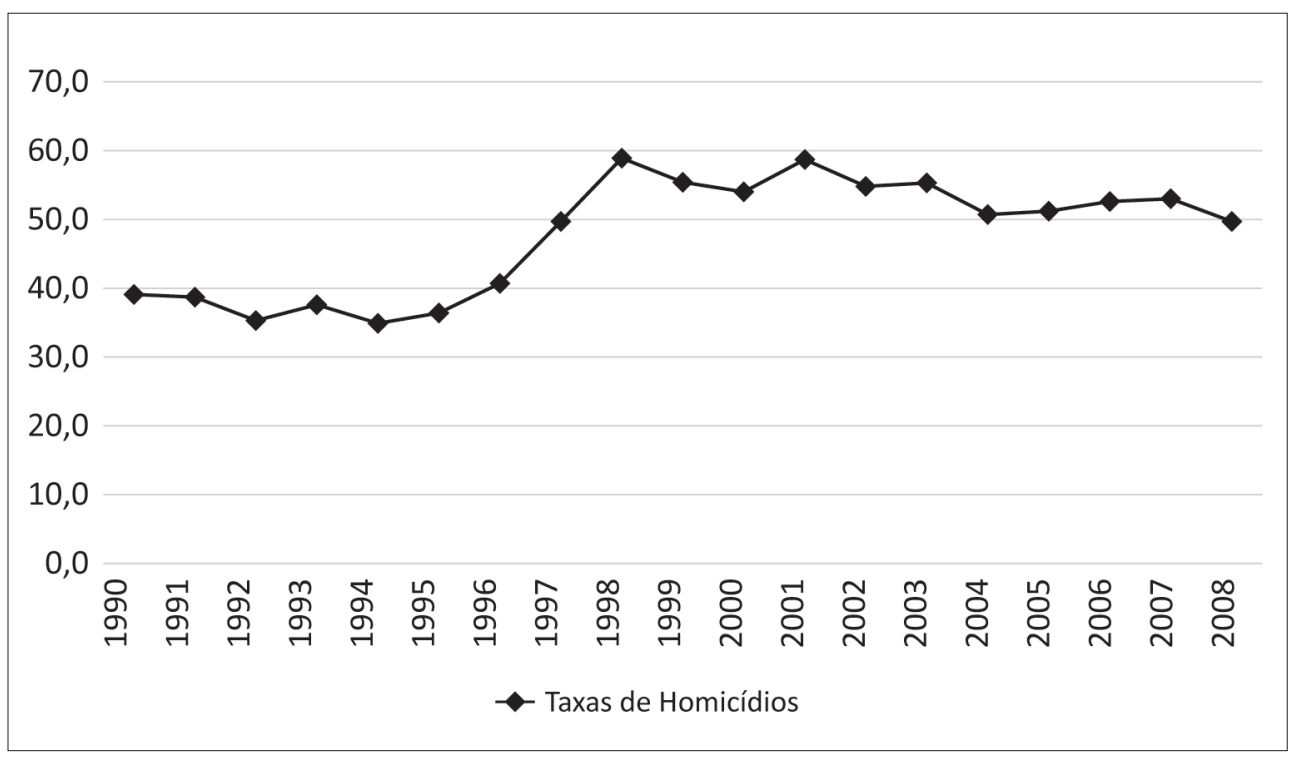

Fonte: SIM/MS (2010)*dados preliminares para o ano de 2008

Gráfico 4. Mortes por agressão por arma de fogo por faixa etária em Pernambuco - 2007

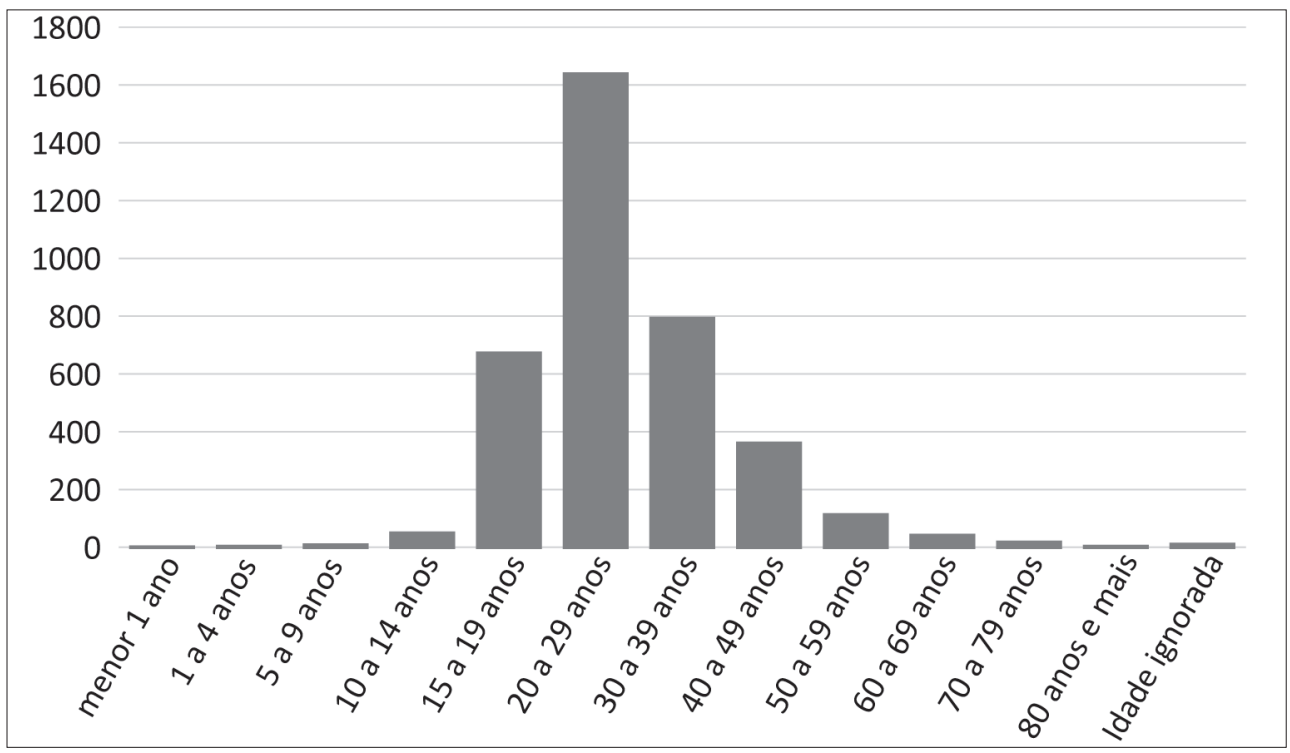


O gráfico 4 demonstra a forte relação entre mortes por agressão/homicídios provocadas por arma de fogo e a faixa etária. É visível que entre 1 e 14 anos de idade tal impacto é insignificante, mas a partir dos 15 anos a vitimização por arma de fogo é crescente. O grupo de risco com maior possibilidade de ser vitimado está entre os 15 e os 39 anos de idade, com destaque para o grupo de 20 a 29. Para o ano de 2007, por exemplo, foram 2.310 mortes no grupo dos 15 aos 29 anos de idade, correspondendo a $63 \%$ do total das vítimas assassinadas por arma de fogo (total de 3.706 no período). Em 2007 foram 4.556 pessoas assassinadas, das quais mais de $80 \%$ vitimadas por arma de fogo em Pernambuco. $\mathrm{O}$ avanço etário é negativamente proporcional ao número de mortes por agressão com arma de fogo, ou seja, o assassinato por arma de fogo é um evento preponderantemente juvenil.

Os homicídios provocados por objetos cortantes ou penetrantes correspondem a pouco mais de $10 \%$ do total de mortes por agressão no estado de Pernambuco. Este é um fator importante, pois muitas pessoas estão sendo mortas por objetos com estas características. Por exemplo, nos anos de 1998, com 521 mortes deste tipo, 2004, com 469, e 2006, com 473 assassinatos, foram computadas mortes que tiveram como arma um objeto cortante ou penetrante, correspondendo de 10\% a 12\% do total dos homicídios do estado (SIM/DATASUS, 2008).

As mortes por meio de objetos contundentes são relativamente altas; correspondem a aproximadamente $5 \%$ do total de mortes por agressão do estado de Pernambuco e vêm sofrendo um incremento bastante significativo nos últimos anos. Os anos de 2002 a 2005 foram significativos para o crescimento deste tipo de agressão, que resulta em óbito da vítima. Houve uma pequena queda em 2006, mas as mortes superam as 270 vítimas. Pode haver alguma relação com o estatuto do desarmamento, que vem retirando armas de fogo de circulação desde 2003, trazendo maior incremento à utilização de outras formas de "armas" (objetos cortantes, penetrantes ou contundentes), com 15\% do total dos homicídios no estado de Pernambuco (SIM/DATASUS; 2008).

As mortes provocadas por agressão neste estado têm como alvo principal os homens. A média de homicídios masculinos para o período 1996-2007 foi de 3.953 assassinatos. Contudo, não é de se desprezar a violência contra a mulher, que tem a média de 278 mortes para a série temporal de 1996 a 2007. O sexo masculino corresponde em média a $90 \%$ dos casos de agressão no estado de Pernambuco. As mulheres ficam em torno de $8 \%$ a $10 \%$ dos casos nos números absolutos (Nóbrega Júnior, 2009).

A relação da cor parda / preta (negros) com as mortes por agressão é significante. Para reforçar esta afirmação, a taxa de pardo/preto para o ano de 2000 foi de 69 hpcmh, enquanto a população total teve uma taxa de 54,2 hpcmh (Nóbrega Júnior, 2009:245). Contudo, o grupo de pardos sofre mais com a vitimização. ${ }^{11}$ 
Em termos de números absolutos, os pardos e os pretos (negros) são vitimados em 84,5\% dos óbitos por agressão, avaliando-se os dados de 2006. Em segundo lugar vem a etnia/cor de pele branca, com 8,5\% (2006). Em terceiro lugar a etnia/ cor de pele preta, com 2\% dos casos (2006). E as etnias/cor de pele amarela e indígena com diminutos impactos.

Escolaridade é uma variável independente que se destaca como importante nos estudos sobre os homicídios. Analisando o gráfico abaixo, observa-se que poucas pessoas são vitimadas por homicídios caso tenham mais de 12 anos de estudo. Já aquelas que possuem entre 8 e 11 anos de escolaridade apresentam certa estabilidade em termos de vitimização, inferior a 81 mortes por agressão, até o ano de 2004. A partir daí inicia-se uma tendência de crescimento, com exceção de 2005, nos anos subsequentes da série histórica. No início da série histórica, em 1999, 67 pessoas foram assassinadas com grau de escolaridade entre 8 e 11 anos. Em 2007, final desta série histórica, foram computados 349 assassinatos, ou seja, mais de $500 \%$ de incremento na série temporal para aqueles que possuem entre 8 e 11 anos de escolaridade.

\section{Gráfico 5. Óbitos por agressão e anos de estudo - Pernambuco 1999 a 2007}

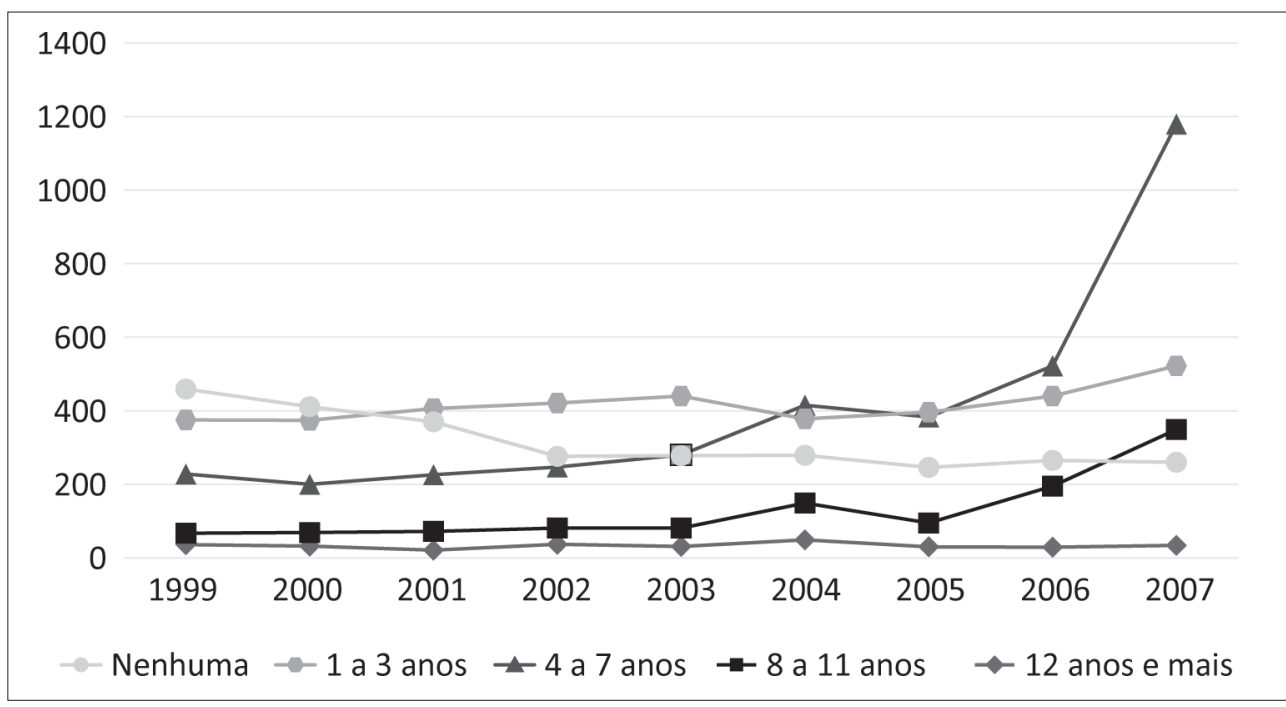

Fonte: SIM/MS

As pessoas que possuem entre 4 e 7 anos de escolaridade vêm em terceiro lugar como o grupo mais vitimado até o ano de 2003, quando praticamente se nivelam com as vítimas sem qualquer escolaridade. A partir de 2001, há uma tendência contínua de crescimento de mortes por agressão de pessoas que possuem entre 
4 e 7 anos de estudo, destacando-se os anos entre 2004 e 2007, quando os homicídios tiveram um aumento de 284\% nesta categoria de escolaridade. Em suma, pode-se concluir que a baixa escolaridade tem uma significativa relação/associação com os homicídios em Pernambuco. ${ }^{12}$

Já no que tange ao estado civil, os solteiros são bem mais atingidos que os casados, mas estes são mais atingidos que os viúvos (geralmente de faixas etárias mais elevadas que, como vimos, são menos vitimados por agressão). Os separados judicialmente são menos atingidos também.

Percentualmente, no ano de 2006, 64\% dos atingidos pelas mortes por agressão foram solteiros; $12 \%$ dos casos foram de casados. Viúvo, separado judicialmente e outros corresponderam a $22 \%$ dos casos em termos de números absolutos (SIM/DATASUS; 2008).

Em Pernambuco a idade média de nupcialidade é de 30 anos entre os homens e de 26,3 anos entre as mulheres (IBGE, 2003), apontando para um fator etário importante. Os homens jovens solteiros são mais atingidos e o grupo mais vitimado está abaixo dos 30 anos de idade e acima dos 15 anos, como foi visto na análise das mortes por agressão versus faixa etária.

\section{Os homicídios nas regiões de Pernambuco}

Apesar da pequena redução dos homicídios no estado de Pernambuco entre 2006 e 2008, seguindo os dados da INFOPOL/SDS-PE, ${ }^{13}$ o crescimento dos homicídios na maioria das regiões do interior deste estado aponta para outra preocupação nos estudos sobre os homicídios. A redução do número absoluto para todo o estado representou uma pequena redução na taxa, menos de $2 \% .{ }^{14}$ Isto não se reflete, em muitos casos, nos dados desagregados por região de desenvolvimento e por municípios. Alguns deles mostram crescimento de mais de 30\% nas suas taxas. Com exceção da Mata Norte, do Sertão do São Francisco e da Região Metropolitana do Recife, ${ }^{15}$ todas as outras regiões de desenvolvimento demonstraram crescimento nos seus indicadores de mortes por agressão/ homicídios /CVLI. ${ }^{16}$ Portanto, pode-se afirmar ser cada vez mais frequente a violência homicida nas cidades interioranas.

A tabela 3 assinala o crescimento da criminalidade na maioria das regiões de desenvolvimento. Na Mata Sul ${ }^{17}$ houve um crescimento, de 2006 para 2007, nos números absolutos de 88 homicídios, o que gerou um aumento percentual de 26\%. A taxa de hpcmh saltou de 50 para 63, um incremento de 13 mortes violentas intencionais por 100 mil habitantes, o que resultou num acréscimo de $12 \%$ na taxa. Em 2008 a região apresentou uma pequena queda nas mortes em seus números absolutos. Menos 22 mortes em relação a 2007, com diminuição de 5\%. Em termos de taxas, decresceu de $63 \mathrm{hpcmh}$ para 59,3, um declínio percentual de $6,5 \%$ nas taxas. 


\section{Tabela 2: Pernambuco - número acumulado de vítimas de crime violento letal e intencional e taxas por 100 mil habitantes, segundo as regiões de desenvolvimento - 2006/2007/2008}

\begin{tabular}{|c|c|c|c|c|c|c|}
\hline Regiões de & \multicolumn{2}{|c|}{2006} & \multicolumn{2}{|c|}{2007} & \multicolumn{2}{|c|}{2008} \\
\hline Vítimas / Taxas & vítimas & taxas & vítimas & taxas & vítimas & taxas \\
\hline Mata Norte & 274 & 50,7 & 230 & 42,6 & 214 & 39,6 \\
\hline Mata Sul & 340 & 50 & 428 & 62,8 & 406 & 59,3 \\
\hline Agreste Central & 462 & 46,8 & 420 & 42,3 & 459 & 45,6 \\
\hline Agreste Meridional & 215 & 35 & 215 & 34,8 & 265 & 42,5 \\
\hline Agreste Setentrional & 172 & 35,5 & 172 & 35,2 & 198 & 40 \\
\hline Sertão Central & 23 & 14 & 39 & 23,5 & 35 & 21 \\
\hline Sertão de Itaparica & 43 & 34 & 43 & 33,5 & 77 & 59 \\
\hline Sertão do Araripe & 64 & 21,7 & 76 & 25,5 & 88 & 29 \\
\hline Sertão do São Francisco & 216 & 54,6 & 180 & 44,4 & 171 & 41 \\
\hline Sertão do Moxotó & 76 & 38,3 & 86 & 42,8 & 88 & 43,2 \\
\hline Sertão do Pajeú & 73 & 23,7 & 74 & 23,9 & 77 & 24,6 \\
\hline Metropolitana & 2.658 & 73,4 & 2.617 & 71,2 & 2.445 & 65,6 \\
\hline Pernambuco & 4.638 & 55,1 & 4.592 & 54 & 4.523 & 52,6 \\
\hline
\end{tabular}

Fonte: INFOPOL/SDS/PE

Municípios localizados na Mata Sul vêm aparecendo constantemente nos noticiários com intensa atividade de tráfico de drogas, sobretudo crack, o que pode ser um indicador do crescimento da violência nesta região. Muitos dos carregamentos descobertos pelas polícias vêm de São Paulo, apontando para um processo migratório da criminalidade organizada do Sudeste para o Nordeste. Em Ribeirão ${ }^{18}$ foi feita uma apreensão recorde de crack em outubro de 2009. Mais de 10 quilos do entorpecente oriundos do estado de São Paulo. ${ }^{19}$

O Agreste Central ${ }^{20}$ apresentou um crescimento nos números de homicídios / CVLI/mortes por agressão de 2007 para 2008, depois de ter decrescido entre 2006 e 2007. A taxa de homicídios por 100 mil habitantes em 2006 foi de 46,8, em 2007 caiu para 42,3, e em 2008 voltou a crescer para 45,6. Entre 2007 e 2008 o incremento percentual nos números absolutos foi de quase $10 \%$, saltando de 420 para 459 mortes, em um total de quase 40 assassinatos a mais entre um ano e outro.

O Agreste Meridional $^{21}$ vinha apresentando uma estabilidade nos números absolutos de CVLI entre 2006 e 2007, 215 assassinatos, com taxas de 35 e 34,8 hmpch, respectivamente, demonstrando queda nas taxas, o que deve ser constatado em função da evolução estimada de sua população. Contudo, em 2008 houve um 
incremento de 40 assassinatos a mais em relação a 2007, o que elevou a taxa de hpcmh para 42,5, ou seja, um impacto percentual de 22\% nas taxas. Garanhuns, principal município desta região por seu peso econômico e político, alavanca os números para cima e vem apresentando números elevados há mais de dez anos.

O mesmo tipo de incremento repete-se no Agreste Setentrional, ${ }^{22}$ onde os homicídios mantiveram-se em 172 nos anos de 2006 e 2007, com taxas de 35,5 e 35,2 hpcmh, praticamente estáveis como os números absolutos. No entanto, em 2008 houve um incremento de mais 26 assassinatos nesta região, o que elevou as taxas de homicídios para 40 por 100 mil habitantes, ou seja, um impacto de 15\% em relação ao ano de 2006. Limoeiro, Santa Cruz do Capibaribe e Surubim destacam-se como as áreas mais violentas, com maior relevância na cidade de Santa Cruz do Capibaribe.

No Sertão Central ${ }^{23}$ também houve um incremento nos números absolutos de um ano para o outro. Em 2006, ocorreram 23 homicídios. Em 2007, este número cresceu para 39, quase dobrando em termos absolutos, e a taxa saltou de $14 \mathrm{hpcmh}$ para 23,5. Em 2008, a região apresentou uma pequena diminuição para 35 mortes por agressão, com a taxa ficando em $21 \mathrm{hpcmh}$, ou menos de $1 \%$ em relação ao ano anterior. Salgueiro, que faz parte do polígono da maconha, ${ }^{24}$ vem tendo impacto significante na atividade do tráfico de drogas. Em julho de 2009, a Polícia Federal apreendeu mais de 10 quilos de cocaína nesta cidade. ${ }^{25}$

Apesar de necessitar de informações consistentes a respeito, neste trecho há indícios de envolvimento de políticos e de alguns atores políticos no que diz respeito ao poder coercitivo estatal na facilitação do desenvolvimento do tráfico de drogas. ${ }^{26}$ Além disso, a demanda vem aumentando entre os habitantes dessa região. Outra informação importante está atrelada ao ganho bem mais lucrativo na produção de maconha que de alimentos, levando muitos agricultores a entrarem no crime.

Desde 2006, o sertão pernambucano vem mostrando crescimento em seus indicadores de CVLI. Em 2009, a Polícia Federal destruiu mais de 1,6 milhões de pés de maconha nesta região. A Operação Catingueira teve como foco 16 cidades, entre elas, Salgueiro, Belém do São Francisco, Serra Telhada e Afogados da Ingazeira. Tal operação fez quatro grandes investidas no Sertão nos meses de fevereiro, maio, agosto e outubro. Com a destruição das lavouras, 549 toneladas da droga deixaram de ser comercializadas. ${ }^{27}$ Contudo, os criminosos migraram para outras práticas, como roubos, assaltos e sequestros. Do mesmo modo, com o esfacelamento dos "negócios" ligados ao tráfico de maconha, estimulou-se a comercialização do crack.

Estas informações não explicam de forma satisfatória o crescimento dos homicídios nessas regiões. Em Floresta, Itacuruba e Carnaubeira da Penha, por exemplo, a maioria dos homicídios tem como motivação o acerto de contas ou "rixa". Muitos outros apresentam como motivação para o crime a "vingança". Poucos assassinatos acontecem em função de dívida de drogas. Apesar de essas 
cidades fazerem parte do "Polígono da Maconha", a droga parece não estar relacionada à maioria dos homicídios ${ }^{28}$ (Batalhão da Polícia Militar do Sertão de Pernambuco, 2008), o que não exaure a discussão, pois crimes motivados por "vingança" e/ ou "rixa" podem ter implicâncias quanto as drogas ou ao consumo de bebidas alcoólicas. ${ }^{29}$

O Sertão de Itaparica ${ }^{30}$ apresentou estabilidade nos anos de 2006 e 2007 em seus números absolutos de mortes por agressão, com 43 mortes deste tipo para os dois anos. As taxas por 100 mil foram de 34 e 33,5 respectivamente, para estes anos. Em 2008, os números foram acrescidos de 34 mortes, ou seja, um impacto percentual de mais de 75\% nos números absolutos, elevando a taxa por 100 mil para 59, praticamente dobrando as taxas. Boa parte dos municípios da região está envolvida no Polígono da Maconha, excluindo Jatobá e Petrolândia. Há intensa atividade de tráfico nessa região. Floresta, uma cidade ali localizada, é constantemente referenciada pela mídia como ponto de comércio e larga negociação de traficantes.

O Sertão do Araripe ${ }^{31}$ foi outra região que mostrou crescimento dos homicídios. O número de mortes em 2006 foi de 64, em 2007 sofreu um acréscimo de mais 12 mortes, ou um aumento de 20\% nos números absolutos. A taxa saltou de 21,7 para 25,5. A grande fragilidade do aparato coercitivo e a corrupção parecem ser pontos que interferem no incremento das mortes. Em 2008, mais um impacto positivo nos números, com mais 12 mortes em relação a 2007, com a taxa saltando para 29 hpcmh e um incremento percentual de 12,5\%. Há fortes indícios da participação de prefeitos e outros políticos em atividades criminosas em algumas cidades desta região.

O Sertão do Moxotó $^{32}$ foi outra região que mostrou aumento em seus indicadores de homicídio. Foram registrados 76 no ano de 2006. O ano de 2007, com dez mortes a mais, registrou 86 assassinatos, com a taxa saltando de 38,3 para 42,8 hpcmh, ou 11,2\% de aumento. Em 2008, os números voltaram a apresentar aumento. Foram 88 assassinatos, com uma taxa por 100 mil habitantes de 43,2 mortes deste tipo. Ibimirim faz parte do Polígono da Maconha, e Arcoverde tem a atividade econômica mais robusta na região; tais fatores podem potencializar a atividade criminosa.

O Sertão do Pajeú ${ }^{33}$ vem apresentando aumento em seus números de homicídios. Em 2006, com 73 mortes; em 2007, com 74; e em 2008, com 77 assassinatos. A taxa saltou de 23,7 em 2006 para 24,6 em 2008, um incremento percentual de $4 \%$ na taxa. Serra Talhada é o município que se destaca em seus números de mortes por agressão, é a principal cidade desta região em termos políticos e econômicos e vem sendo citada como ponto importante no comércio de drogas.

As reais causas para essa dinâmica precisam ser mais bem explicadas. Dados do policiamento militar do Sertão apontam para o crescimento de prisões, e isto se reflete no aumento da população carcerária de Pernambuco que, de 2000 a 2007, 
mais que dobrou (DEPEN/InfoPEN, 2008). A PM sertaneja tem apreendido armas e efetuado prisões, juntamente com a Polícia Civil, de forma crescente, mas não tem alcançado redução significativa nos homicídios. O gráfico abaixo ilustra um pouco esta afirmação.

\section{Gráfico 6. Resultados de prisões, apreensão de armas de fogo e homicídios em Serra Talhada entre janeiro e outubro de 2008}

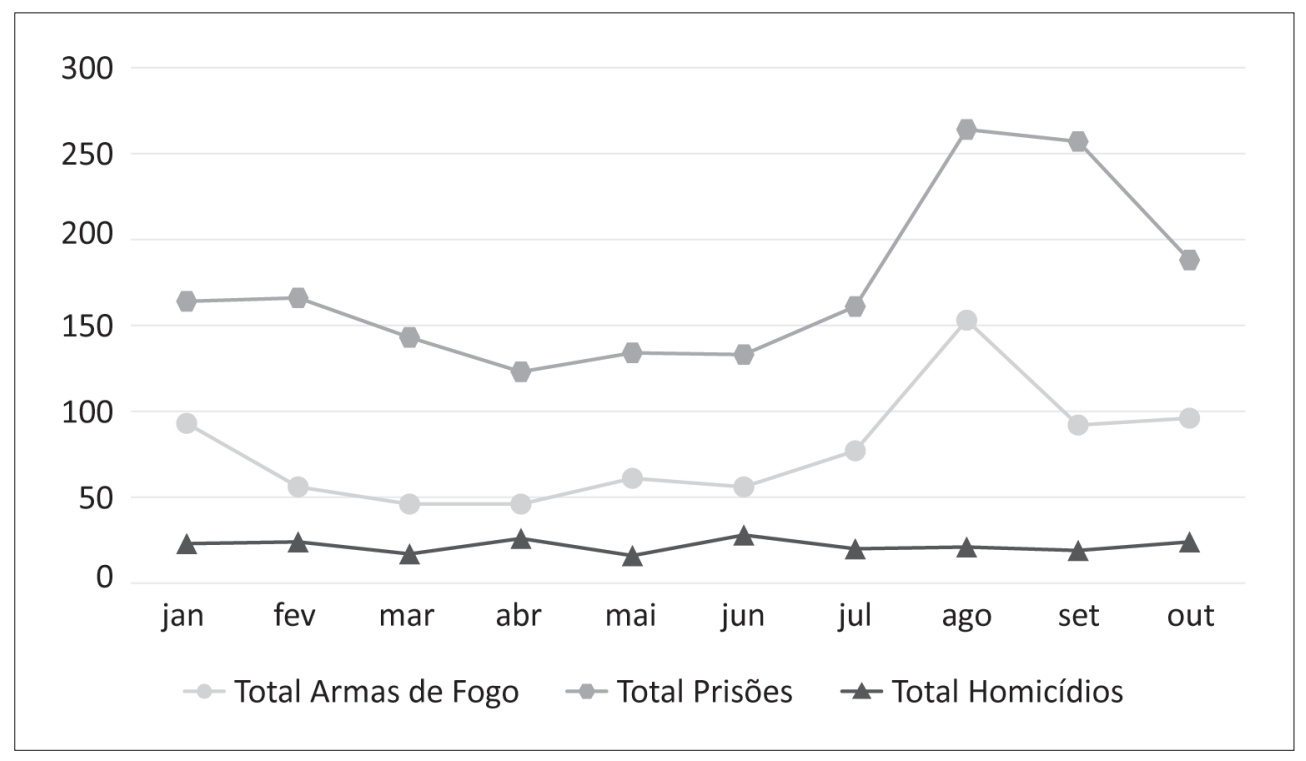

Fonte: Polícia Militar do Sertão de Pernambuco (2008)

(Dados não consolidados para outubro)

Alguns dos municípios mais populosos de Pernambuco apontam também incrementos positivos nos indicadores de violência, apesar do pequeno decréscimo nos dados agregados do estado. Em Recife, a capital, houve redução na taxa, caindo de 72 para 63 hpcmh de 2006 para 2008. Isto indica a tendência de queda na RMR refletida no total dos homicídios ocorridos no estado.

Como demonstra a tabela 3, Cabo de Santo Agostinho, Caruaru, Garanhuns, Paulista e Vitória de Santo Antão confirmaram aumentos importantes nas taxas, com destaque para Cabo de Santo Agostinho e Vitória de Santo Antão. O destaque positivo foi o município de Petrolina, que faz parte do "Polígono da Maconha", mas que teve redução significativa na sua taxa, decaindo de 59,5 em 2006 para 48 em 2008, uma redução na ordem de 20\%. Estes dados indicam, por outro lado, que a mera relação entre tráfico de drogas e homicídios, sem levar em consideração outros aspectos como o crescimento da atividade econômica - que pode gerar mais 
oportunidades de emprego e, por sua vez, mais dinheiro em circulação, trazendo o consequente consumo de drogas e álcool e as práticas de crimes contra o patrimônio - ou o papel das políticas públicas de segurança, mostra-se frágil. ${ }^{34}$

\section{Tabela 3: Pernambuco - Taxa anual de criminalidade violenta letal e intencional da população total por tamanho da população}

\begin{tabular}{|l|c|c|c|}
\hline \multicolumn{1}{|c|}{ Municípios } & $\mathbf{2 0 0 6}$ & $\mathbf{2 0 0 7}$ & $\mathbf{2 0 0 8}$ \\
\hline Cabo de Santo Agostinho & 86,4 & 97,84 & 104 \\
\hline Camaragibe & 60,5 & 48,3 & 48,6 \\
\hline Caruaru & 57,9 & 50,6 & 54,3 \\
\hline Garanhuns & 37,9 & 45,5 & 62,5 \\
\hline Jaboatão dos Guararapes & 84,4 & 82,2 & 74 \\
\hline Olinda & 71 & 67,8 & 68 \\
\hline Paulista & 61,6 & 64,7 & 55,6 \\
\hline Petrolina & 59,5 & 49,6 & 63 \\
\hline Recife & 72 & 68 & 71,3 \\
\hline Vitória de Santo Antão & 55,5 & 65,1 & 52,5 \\
\hline Pernambuco & 55,1 & 54 & \\
\hline
\end{tabular}

Fonte: INFOPOL/SDS/PE

Apesar de algumas reduções nas taxas e da captura de certos grupos ilícitos, como foi o caso dos Thunder Cats em Jardim São Paulo, ${ }^{35}$ a manutenção do tráfico de drogas, da interiorização da sistemática do tráfico, da migração do crime do Sudeste para o Nordeste, da participação de policiais em grupos de extermínio e da milícia fora da lei, da ineficácia do processo de investigação por parte da polícia civil, da lentidão da justiça, da fragilidade no controle da variável jovem e do abandono do sistema penitenciário é a determinante dos fatores decisivos para as altíssimas taxas de homicídios em Pernambuco (Nóbrega Jr., 2010).

\section{Gastos/investimentos em segurança pública em Pernambuco e sua relação com os homicídios}

Esta seção tem o propósito de avaliar o impacto dos gastos/investimentos diretos em segurança pública em relação aos homicídios em Pernambuco. Não atestamos a qualidade desses gastos, focamos apenas na associação quantitativa entreosdadosdegastos/investimentosemsegurançacomosindicadoresdehomicídios para o referido estado. Aqui se procura responder ao seguinte questionamento: Qual a relação dos gastos públicos em segurança com os homicídios em Pernambuco?

Entre 2001 a 2008, os recursos investidos em segurança pública foram crescentes. Nesse período, o incremento percentual em gastos com segurança em 
Pernambuco foi de 80\%. Em 2001, num total de R \$ 511,3 milhões; em 2006, $\mathrm{R} \$ 881,7$ milhões; em 2007, em torno de $\mathrm{R} \$ 780$ milhões, com novo crescimento em 2008, na ordem de R \$ 919 milhões.

O gráfico abaixo demonstra duas fases de investimentos em segurança em Pernambuco. A primeira, entre os anos de 2001 e 2004, com gastos entre R\$ 511 e R\$ 650 milhões. E a segunda, com gastos entre R\$ 780 e R\$ 919 milhões, entre os anos de 2005 e 2008. Apesar de anos de queda nos investimentos, como 2003 em relação a 2002, e 2007 em relação a 2006, o segundo período da série histórica demonstra maior impacto nos gastos nesta pasta para Pernambuco. Analisando os dados de homicídios do banco de dados do SIM, percebe-se que os mais robustos nesse segundo período não influenciaram o combate à violência homicida, já que houve crescimento constante nos números absolutos entre 2005 e 2007, à exceção de 2008. ${ }^{36}$

\section{Gráfico 7. Investimentos/gastos em segurança pública realizados pelo estado de Pernambuco - 2001 a 2008}

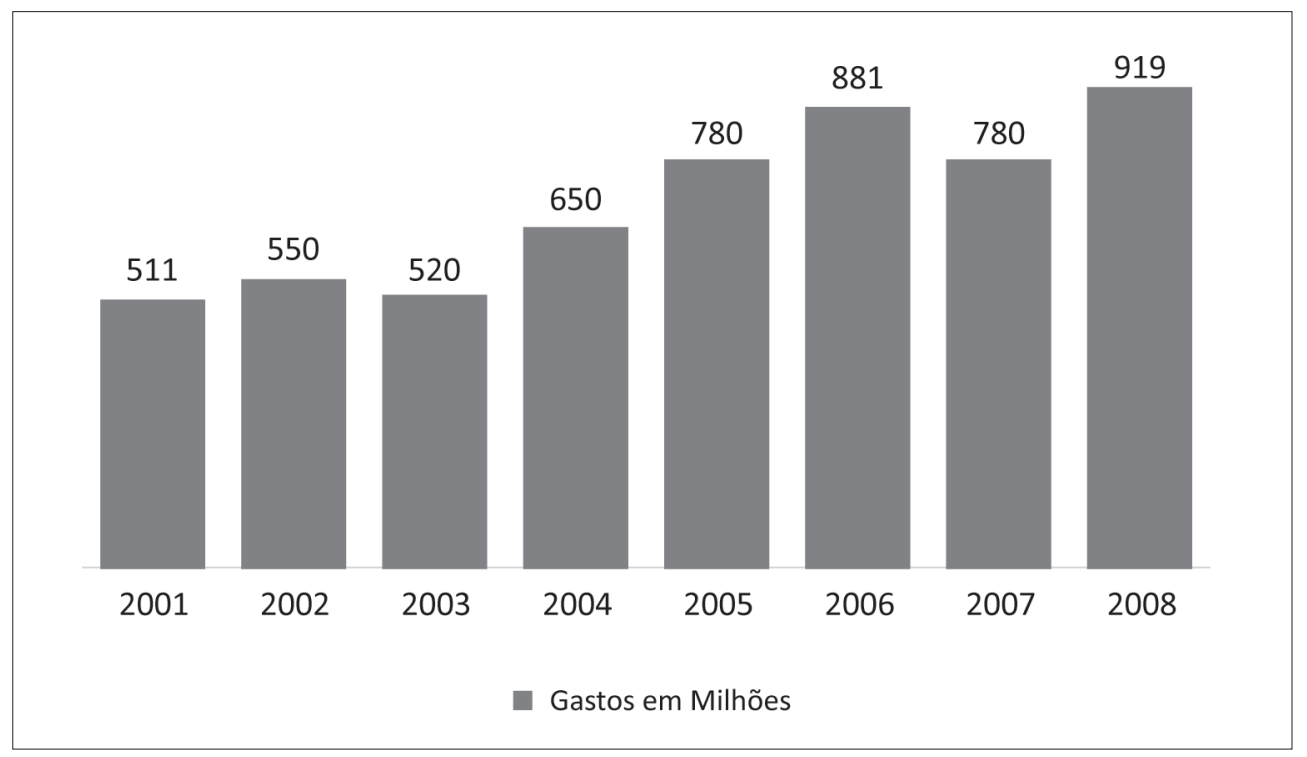

Fonte: Relatórios do governo do estado de Pernambuco (http: / /www.portaldatransparência.pe.gov.br)

A alta frequência dos homicídios em Pernambuco fez com que o governo investisse mais em segurança pública ano após ano, com exceção de 2003 e 2007. Portanto, gastar/investir mais na segurança pública significa a busca de soluções para o problema da criminalidade. Essas dotações serviram para melhor aparelhar as instituições coercitivas estatais que, com sua presença, diminuíram os espaços físicos para o cometimento dos crimes, da violência e/ou dos delitos. 
Uma relação ou uma necessidade perversa poderá existir, ou seja, gastar mais em segurança sem a redução satisfatória dos índices de criminalidade, em particular a frequência de homicídios, fará com que mais recursos precisem ser disponibilizados. Sendo assim, se um governo anualmente aumenta os gastos em segurança pública, mas não comprova a redução dos índices de criminalidade, poderá ter que disponibilizar mais recursos.

Com base nesta hipótese, no gráfico abaixo é possível observar que há dois indicadores: taxas de homicídios por 100 mil habitantes e gastos com segurança pública em milhões de reais em determinado período. No ano de 2001, a taxa de homicídios teve o seu ápice no período analisado: 58,8 homicídios por 100 mil habitantes. Em contrapartida, os recursos gastos com segurança foram os menores do período.

\section{Gráfico 8. Taxas de homicídios versus gastos com segurança pública 2001 a 2008}

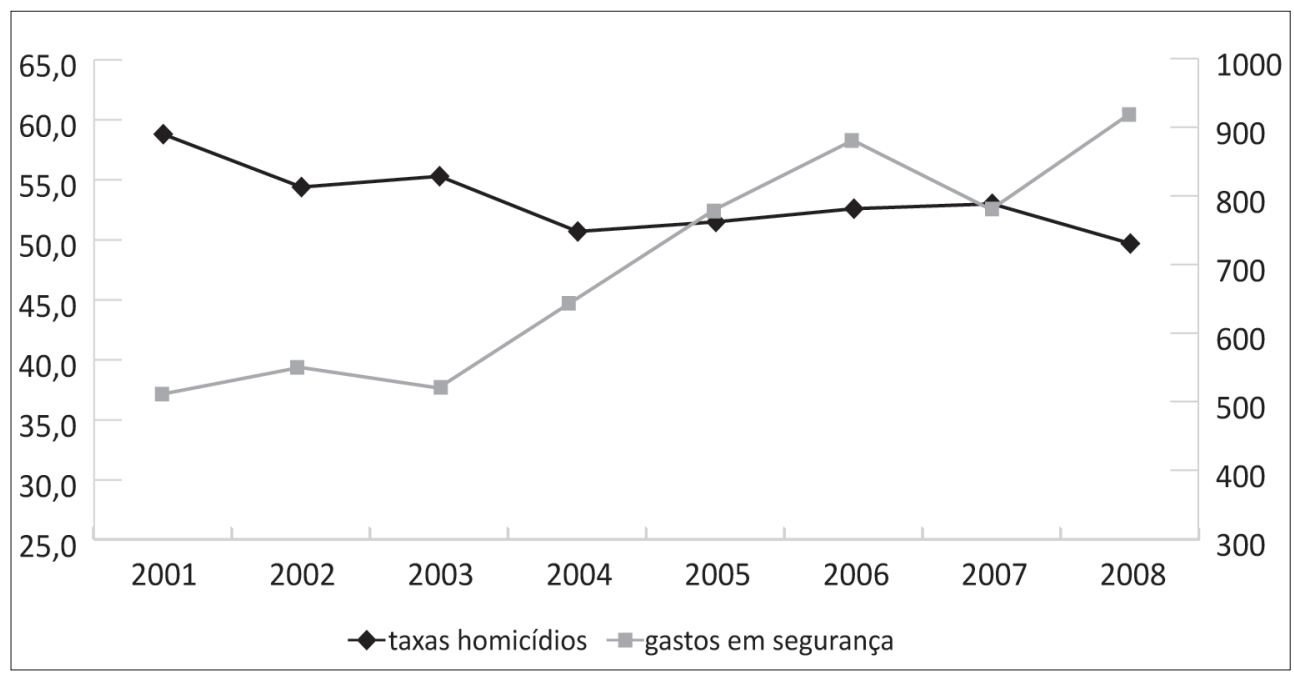

Fontes: Relatórios do governo do estado de Pernambuco - Taxas de homicídios do Autor (SIM) (http://www.portaldatransparência.pe.gov.br)

No ano de 2002 a taxa de homicídio foi de 54,4 hpcmh. Em 2003 os homicídios voltaram a crescer, 55,3. Eles decresceram novamente em 2004, 50,7; mas em 2005 cresceram mais uma vez, 51,2; em 2006 houve novo crescimento para 52,6; em 2007 os homicídios praticamente permaneceram no mesmo patamar do ano anterior, com 53 hpcmh; e em 2008 houve nova queda, com a taxa decaindo para 49,7 hpcmh, a menor desde 1998.

Aí existe uma relação mais impactante entre os gastos públicos em segurança e a queda dos homicídios, o ano de 2008 expressando o maior gasto em todo o período analisado. Contudo, há uma tendência da série histórica (2001 a 2008) 
de estabilidade dos homicídios, mesmo com os gastos crescentes em segurança (lembrar que os gastos tiveram um incremento de $80 \%$ entre 2001 e 2008), com os homicídios caindo de 58,8 por 100 mil habitantes em 2001 para 49,7 em 2008, numa variação de $15,5 \%$ aproximadamente.

Dessa forma, apontar uma relação causal entre gastos/investimentos em segurança pública e decréscimo da violência/homicídios entre 2001 e 2008 não é possível nesse período, já que ele é curto para uma análise mais sofisticada. Mesmo assim, uma correlação entre os gastos públicos em segurança e os homicídios em Pernambuco pode ser satisfatória a longo prazo, mas para isto será preciso analisar uma série histórica mais extensa.

Concluindo: é incipiente a afirmação de que os gastos/investimentos públicos em segurança em Pernambuco são a variável determinante para a redução dos homicídios. O aumento dos gastos em segurança per si pouco nos diz sobre a eficiência das instituições coercitivas no combate à criminalidade.

\section{A queda da desigualdade e da pobreza e os homicídios no Nordeste}

Boa parte da literatura nacional e internacional que trabalha com a questão da violência associa desigualdade e pobreza a fatores causais fundamentais. Alguns trabalhos importantes apontam para relação entre desigualdade/pobreza e criminalidade violenta (Beato \& Reis, 2000; Cerqueira, Lobão \& Carvalho, 2007). Mas quando o foco da análise é o homicídio na região Nordeste, o resultado contradiz a teoria.

Entre 2001 e 2005 a desigualdade de renda declinou substancialmente no Brasil, e de forma contínua, alcançando neste último ano o menor nível das últimas três décadas. Além de relevante por si só, esta desconcentração teve consequências expressivas sobre a pobreza e a extrema pobreza no país. A despeito do lento crescimento econômico, a extrema pobreza declinou para uma taxa seis vezes mais acelerada que a requerida pela primeira meta do primeiro objetivo de desenvolvimento do milênio (Barros et al., 2006:9).

As políticas de distribuição de renda do governo, como as pensões e as aposentadorias, o Benefício de Prestação Continuada (BPC) e o Programa Bolsa Família (PBF), foram fundamentais para a queda da desigualdade e a melhoria na condição de vida das pessoas (Barros et al., 2006).

A Pesquisa Nacional por Amostra de Domicílios (Pnad) demonstrou que, de 1995 a 2005, houve uma tendência à queda na desigualdade de rendimento domiciliar per capita (RDPC), este decréscimo tendo se mostrado mais relevante a partir de 2001. O índice de Gini da distribuição do rendimento domiciliar per capita (RDPC) caiu de 0,594 em 2001 para 0,566 em 2005. Essa redução de $4,8 \%$ no indicador de Gini em quatro anos pode parecer pequena, mas cabe assinalar que o valor absoluto de sua intensidade anual é semelhante ao do crescimento de 
oito pontos percentuais do índice de Gini do rendimento mensal total de pessoas economicamente ativas com rendimento positivo (PEA) no Brasil, na década de 1960, que mereceu grande destaque na literatura sobre distribuição de renda e no debate político (Nóbrega Jr., 2009a:78).

Outros indicadores de desigualdade confirmam essa tendência. A percentagem da renda apropriada pelos 10\% mais ricos caiu de 47,2\% em 2001 para 45\% em 2005, ao mesmo tempo em que a percentagem da renda total recebida pelos $5 \%$ mais ricos caiu de 33,8\% para 32\%. Em 2001 a percentagem da renda total apropriada pelo $1 \%$ mais rico $(13,8 \%$ ) ainda era maior do que a percentagem da renda apropriada pelos 50\% mais pobres (12,7\%). A situação inverteu-se em 2005, ficando $12,9 \%$ para o centésimo mais rico e $14,2 \%$ para a metade mais pobre (Hoffmann, 2006:96, 97).

Na região Nordeste o índice de renda das pessoas que se apropriam da renda equivalente ao 1\% mais rico sofreu uma redução de aproximadamente cinco pontos percentuais entre os anos de 2001 e 2005, como se observa na tabela abaixo:

\section{Tabela 4: Renda apropriada 1\% mais rico - Região Nordeste}

\begin{tabular}{|c|c|c|c|c|c|}
\hline Região & $\mathbf{2 0 0 1}$ & $\mathbf{2 0 0 2}$ & $\mathbf{2 0 0 3}$ & $\mathbf{2 0 0 4}$ & $\mathbf{2 0 0 5}$ \\
\hline Nordeste & 30,50 & 30,50 & 28,34 & 27,29 & 25,25 \\
\hline
\end{tabular}

Fonte: IPEADATA

A redução de domicílios pobres na região Nordeste foi constante entre 2001 e 2005. Percebe-se que houve um decréscimo de cinco pontos percentuais em relação à pobreza neste indicador:

\section{Tabela 5: Pobreza - domicílios pobres (\%) - Região Nordeste}

\begin{tabular}{|c|c|c|c|c|c|}
\hline Região & $\mathbf{2 0 0 1}$ & $\mathbf{2 0 0 2}$ & $\mathbf{2 0 0 3}$ & $\mathbf{2 0 0 4}$ & $\mathbf{2 0 0 5}$ \\
\hline Nordeste & 0,51 & 0,50 & 0,51 & 0,49 & 0,44 \\
\hline
\end{tabular}

Fonte: IPEADATA

Em Alagoas, em 2001, 33,89\% correspondiam às pessoas que se apropriavam da renda equivalente ao $1 \%$ mais rico da população; isto caiu para $22,34 \%$, em 2005. Na Bahia, em 2001, eram 29,4\%, já em 2005 caiu para 21,4\%. No Ceará, em 2001, eram 35\%, em 2005 caiu para 26\%. No Maranhão houve uma queda considerável, de 26\% em 2001 para 18,7\% em 2005. Na Paraíba, em 2001, eram $30,5 \%$ as pessoas que se apropriavam da renda equivalente ao $1 \%$ mais rico da população, em 2005 caiu para 28,3\%. Em Pernambuco, em 2001, eram 32,7\% 
os que correspondiam ao 1\% mais rico da população, em 2005 caiu para 28,3\%. No Piauí, estado mais pobre da região Nordeste, em 2001 eram 30,5\% as pessoas que se apropriavam da renda equivalente ao $1 \%$ mais rico, em 2005 caiu para $29,4 \%$. O Rio Grande do Norte, único estado em que cresceu a concentração, em 2001 eram 25,2\% as pessoas que se apropriavam da renda equivalente ao $1 \%$ mais rico da população, em 2005 cresceu para 30,5\%. Sergipe foi o estado que manteve sua média de 18,7\% em quase todos os períodos, exclusive em 2003, com crescimento de aproximadamente quatro pontos percentuais.

\section{Tabela 6: Pessoas que se apropriam da renda equivalente ao $1 \%$ mais rico $(\%)$ \\ Estados nordestinos}

\begin{tabular}{|l|c|c|c|c|c|}
\hline \multicolumn{1}{|c|}{ Estados } & $\mathbf{2 0 0 1}$ & $\mathbf{2 0 0 2}$ & $\mathbf{2 0 0 3}$ & $\mathbf{2 0 0 4}$ & $\mathbf{2 0 0 5}$ \\
\hline Alagoas & 34 & 36,2 & 34 & 25,2 & 22,3 \\
\hline Bahia & 29,4 & 30,5 & 30,5 & 22,3 & 21,4 \\
\hline Ceará & 35,0 & 27,2 & 23,2 & 26,2 & 26,2 \\
\hline Maranhão & 26,2 & 29,4 & 29,4 & 37,4 & 18,7 \\
\hline Paraíba & 30,5 & 34 & 24,2 & 30,5 & 28,3 \\
\hline Pernambuco & 32,7 & 30,5 & 28,3 & 32,7 & 28,3 \\
\hline Piaú́ & 30,5 & 38,6 & 30,5 & 30,5 & 29,4 \\
\hline Rio Grande do Norte & 25,2 & 21,4 & 21,4 & 22,3 & 30,5 \\
\hline Sergipe & 18,7 & 18,7 & 22,3 & 18,7 & 18,7 \\
\hline
\end{tabular}

Fonte: IPEADATA

Em todos os estados do Nordeste houve uma redução dos domicílios pobres, indicador importante para a análise do crescimento ou do decréscimo da pobreza, como podemos observar na tabela 7.

\section{Tabela 7: Pobreza - domicílios pobres (\%) - Nordeste}

\begin{tabular}{|l|l|l|l|l|l|}
\hline \multicolumn{1}{|c|}{ Estados } & $\mathbf{2 0 0 1}$ & $\mathbf{2 0 0 2}$ & $\mathbf{2 0 0 3}$ & $\mathbf{2 0 0 4}$ & $\mathbf{2 0 0 5}$ \\
\hline Alagoas & 0,56 & 0,57 & 0,58 & 0,55 & 0,51 \\
\hline Bahia & 0,50 & 0,48 & 0,50 & 0,45 & 0,42 \\
\hline Ceará & 0,49 & 0,47 & 0,48 & 0,48 & 0,43 \\
\hline Maranhão & 0,56 & 0,56 & 0,58 & 0,56 & 0,50 \\
\hline Paraíba & 0,54 & 0,49 & 0,48 & 0,48 & 0,42 \\
\hline Pernambuco & 0,51 & 0,50 & 0,53 & 0,51 & 0,47 \\
\hline
\end{tabular}




\begin{tabular}{|l|l|l|l|l|l|}
\hline Piauí & 0,53 & 0,54 & 0,53 & 0,52 & 0,49 \\
\hline Rio Grande do Norte & 0,45 & 0,44 & 0,48 & 0,44 & 0,39 \\
\hline Sergipe & 0,46 & 0,42 & 0,42 & 0,38 & 0,37 \\
\hline
\end{tabular}

Fonte: IPEADATA

Em relação aos homicídios, entre 2001 e 2005, estes cresceram significativamente em toda a região (Tabela 8 ), inclusive nos estados mais pobres onde houve melhoria em alguns importantes indicadores socioeconômicos. O Piauí, por exemplo, apesar da melhoria de seu índice socioeconômico, demonstrou incremento nos homicídios. As taxas de homicídio em sua população total foram de nove por 100 mil habitantes em 2001. Disparou continuamente até alcançar mais de $12 \mathrm{hpcmh}$, em 2005 (SIM/MS). Se formos apontar uma relação entre os indicadores socioeconômicos e os homicídios, esta foi inversa.

\section{Tabela 8: Números absolutos de homicídios na região Nordeste e estados - 2001 a 2005}

\begin{tabular}{|l|c|c|c|c|c|}
\hline \multicolumn{1}{|c|}{ Região Nordeste } & $\mathbf{2 0 0 1}$ & $\mathbf{2 0 0 2}$ & $\mathbf{2 0 0 3}$ & $\mathbf{2 0 0 4}$ & $\mathbf{2 0 0 5}$ \\
\hline Maranhão & 10592 & 10965 & 11861 & 11581 & 12986 \\
\hline Piauí & 562 & 606 & 792 & 729 & 935 \\
\hline Ceará & 262 & 308 & 298 & 327 & 368 \\
\hline Rio Grande do Norte & 1284 & 1444 & 1562 & 1582 & 1697 \\
\hline Paraíba & 322 & 299 & 405 & 344 & 406 \\
\hline Pernambuco & 484 & 607 & 615 & 675 & 745 \\
\hline Alagoas & 4709 & 4396 & 4517 & 4174 & 4329 \\
\hline Sergipe & 830 & 991 & 1039 & 1035 & 1203 \\
\hline Bahia & 517 & 555 & 469 & 454 & 487 \\
\hline
\end{tabular}

Fonte: SIM/DATASUS

Independentemente das melhorias nos indicadores apontados nesta seção, percebe-se claramente que os homicídios vêm percorrendo caminho inverso no Nordeste. Os homicídios cresceram sem que houvesse relação com a diminuição da pobreza e da desigualdade de renda.

\subsection{O Programa Bolsa Família e sua relação com os homicídios}

Desde a implementação do Programa Bolsa Família (PBF), em 2003, os investimentos têm sido crescentes, resultando em um aumento médio de 12,46\% ,em 2006. Em relação aos investimentos nos serviços sociais básicos e universais, nos três primeiros anos (entre 2003 e 2005) do Bolsa Família houve 
uma taxa de crescimento em investimentos na ordem de 103,64\%. O aumento dos gastos sociais arrefeceu a desigualdade e a pobreza, dimensionando o papel do Programa Bolsa Família.

A partir da unificação dos programas de transferência de renda existentes para o Programa Bolsa Família em 2003, o incentivo a essa política de transferência de renda aumentou em quase 20\% a participação do Ministério do Desenvolvimento Social e Combate à Fome (MDS). Neste espaço será analisada a evolução do investimento no Programa Bolsa Família entre 2004 e 2007 e sua relação com os homicídios.

Em 2004 os gastos federais no programa ultrapassaram os R \$ 5,5 bilhões; já em 2007, esses gastos superaram o nível dos R\$ 7 bi (Cf. gráfico 9). Em comparação ao crescimento da taxa média da economia nacional para o mesmo período, inferior a 5\%, tem-se a dimensão do impacto de tal crescimento no gasto com esse programa social, pois as despesas com o Bolsa Família ultrapassaram duas vezes o nível da economia brasileira.

\section{Gráfico 9. Evolução das transferências para o Programa Bolsa Família no Brasil (em R\$)}

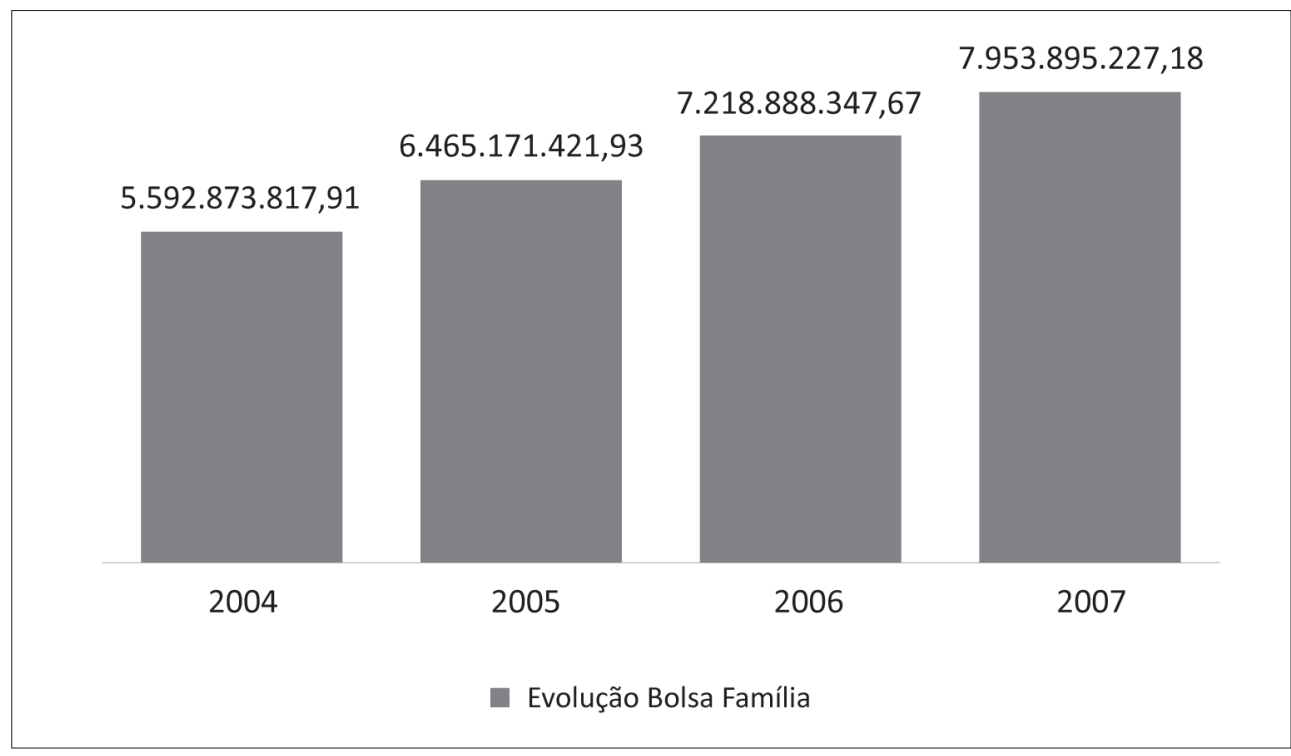

Fonte: Controladoria Geral da União (CGU)

De acordo com os gastos alocados para o programa, percebe-se que a maior participação relativa a eles se dá na região Nordeste, na ordem de 52,99\%. A região Sudeste apresenta a segunda maior participação relativa (23,8\%). Embora seja a região mais rica do país pela sua diversificada economia, é também a mais populosa, 
o que resulta numa grande retenção dos recursos do programa nesta região. A região Centro Oeste apresentou a menor participação relativa do programa $(4,43 \%)$, o que pode ser explicado também pela variável demográfica, sendo a região menos populosa, com extensos vazios demográficos.

\section{Gráfico 10. Participação relativa em termos percentuais no Programa Bolsa Família por região do Brasil (2004 a 2007)}

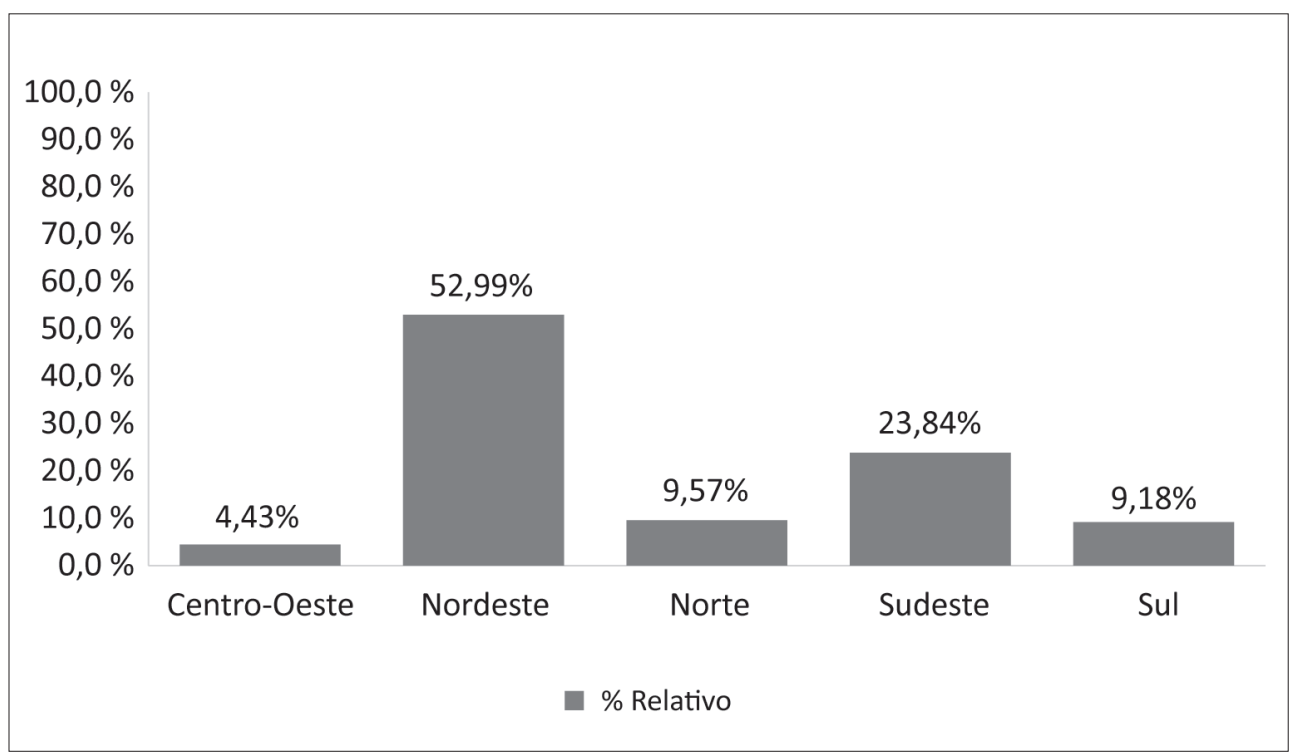

Fonte: Controladoria Geral da União

A região Nordeste apresentou a seguinte distribuição em termos de investimentos/gastos sociais percentuais relativos no PBF:

A Bahia apresentou o maior investimento (13,51\%), seguida do Ceará $(7,98 \%)$. Pernambuco apresentou o terceiro impacto relativo com 7,98\% de investimento, em terceiro lugar. $\mathrm{O}$ menor índice de investimento esteve localizado em Sergipe, com 1,84\% (período 2004 a 2007).

Por outro lado, entre 2004 e 2007, os homicídios evoluíram positivamente na região Nordeste. Foi visto que o maior investimento/gasto relativo do governo esteve focado nesta região, no entanto, a violência permaneceu em estado crescente, apesar desses investimentos. Por exemplo, a Bahia, que teve o maior investimento / gasto do PBF do Nordeste, apresentou um incremento percentual nos números absolutos de homicídios na ordem de 300\% entre 2004 e 2007 (Vide gráfico 2).

Nesse período, os homicídios sofreram um incremento de $34 \%$ em seus números absolutos na região, saltando de 11.581 assassinatos em 2004 para 15.432 
em 2007 (SIM/DATASUS, 2009). Os gastos com o PBF tiveram um impacto de $53 \%$ nos investimentos relativos para o Nordeste, com despesas que ultrapassaram os R $\$ 14$ bilhões.

\section{Gráfico 11. Participação relativa em termos percentuais no Programa Bolsa Família nos estados nordestinos (2004 a 2007)}

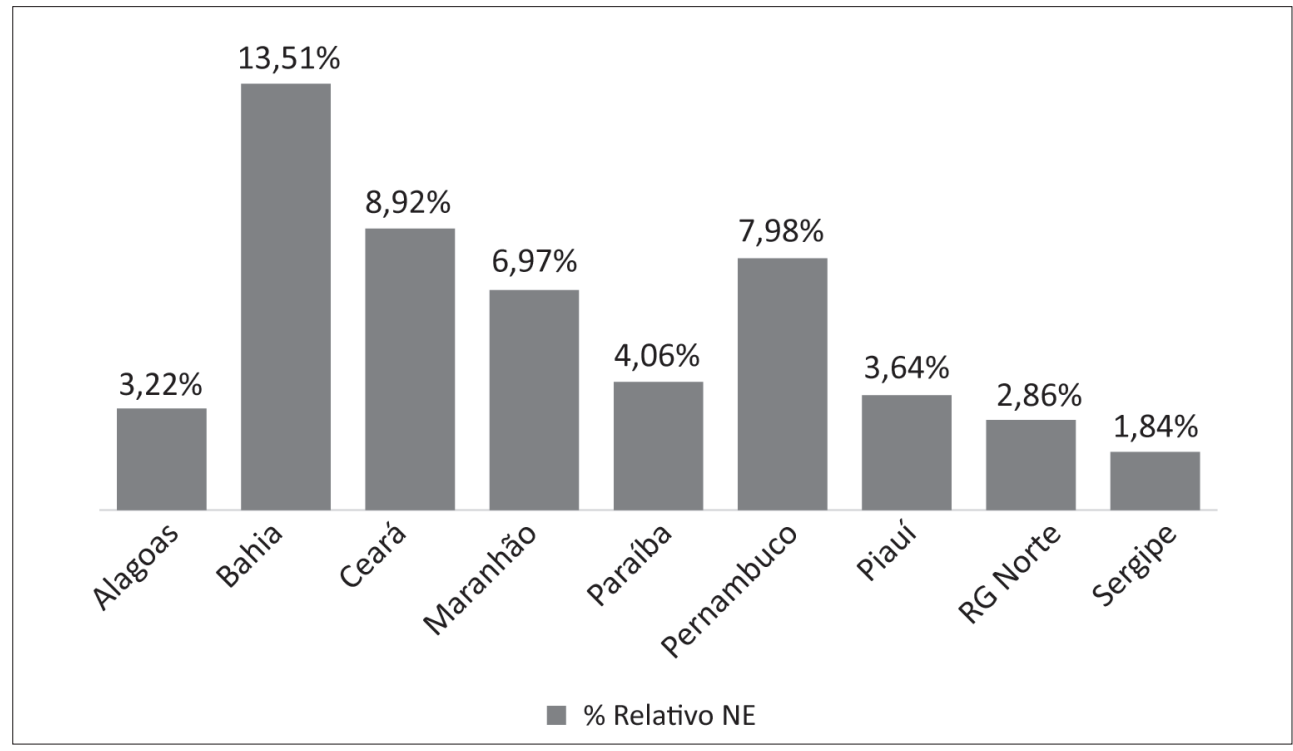

Fonte: Controladoria Geral da União

Reforçando a falta de relação/associação entre desigualdade/pobreza e violência, parece pouco provável que a melhoria estrutural seja condicionante para o controle e a redução da violência (proxy $=$ homicídios).

\section{Conclusão}

Os homicídios no Nordeste vêm crescendo independente das melhorias estruturais, como foi visto na relação entre os homicídios e as macrovariatas socioeconômicas elencadas de acordo com a literatura sobre o assunto. A teoria de que o desenvolvimento econômico, a diminuição da desigualdade (social e de renda) e da pobreza são fatores decisivos para o controle da violência (proxy=homicídios) não se comprovou no caso desta região, especificamente em Pernambuco.

Segundo o relatado, há fortes indicativos do crescimento da criminalidade violenta no interior de Pernambuco e do robustecimento de crimes relacionados ao tráfico de drogas e ao consumo de álcool. O desenvolvimento econômico encontrado em algumas cidades do interior, nas diversas regiões de desenvolvimento, pode estar potencializando o consumo de drogas e de álcool e, por sua vez, a prática dos homicídios. 
Os governos de Pernambuco vêm gastando/investindo mais em segurança pública sem um efetivo controle da variável homicídio. Os gastos são crescentes, pelo menos, desde 2001, com um aumento real de $80 \%$ brutos na área. Contudo, a inflexão dos números de homicídios não se faz satisfatória para o período analisado.

A melhoria na condição de vida das pessoas em todo o Nordeste é visível. Indicadores socioeconômicos (as macrovariatas) praticamente melhoraram em todos os níveis estaduais no Nordeste, mas os homicídios tiveram relação inversa a tal melhora, ou seja, continuam ocorrendo frequentemente crimes violentos letais e intencionais, independente do esforço do governo em políticas de renda, sociais e de desenvolvimento econômico.

Dessa forma, tais variáveis independentes (PIB, renda per capita, percentual de domicílios pobres, Bolsa Família etc.) podem até abrir caminho para o robustecimento de práticas delituosas, como consumo e tráfico de drogas, e o seu reflexo imediato, a violência, inclusive homicida, caso outros mecanismos de contenção não sejam executados.

No Nordeste, diferente do que ocorre no Sul e no Sudeste, as causas da violência homicida são diferenciadas. O Nordeste segue caminho distinto quando são analisadas as mesmas variáveis que, em muitos trabalhos, vêm apresentando relevância em graus de associação/correlação entre as variáveis socioeconômicas (macrovariatas) e os homicídios.

Todavia, a dinâmica dos homicídios segue caminhos parecidos em relação às suas vítimas. Algumas diferenças pontuais podem ser encontradas, mas geralmente essas pessoas são homens jovens, vitimados por arma de fogo, de baixa renda, vivendo em ambientes socialmente desajustados, com envolvimento com tráfico e/ou consumo de drogas. Muitas vezes, a desigualdade e a pobreza podem motivar a entrada do indivíduo no mundo do crime. Mas isto per si não explica o problema. Como foi visto, alguns estados nordestinos aumentaram sua renda diminuindo a desigualdade e a pobreza - mas os índices de criminalidade cresceram significativamente em todos eles - com destaque para a Bahia - não obstante a melhoria de seus indicadores socioeconômicos.

Esta constatação sugere que outras variáveis precisam ser estudadas, tais como a corrupção das instituições coercitivas e sua ineficiência na elucidação dos homicídios e na punição dos homicidas. 


\section{Notas}

1. Violência homicida, homicídios, mortes por agressão e óbitos por agressão aparecem neste trabalho como sinônimos.

2. Para avaliar os dados de homicídios e a formatação dos bancos de dados de violência, ver Nóbrega Jr. (2010). Os homicídios têm como foco as mortes violentas provocadas intencionalmente por outras pessoas, não seguindo uma definição meramente jurídica do termo.

3. Proxy, numa linguagem estatística, é o mesmo que substituto, ou seja, como violência é um fenômeno muito amplo para que possamos medi-lo minimamente; a utilização de variáveis é fundamental. Na literatura quantitativa sobre a violência, os homicídios são utilizados geralmente como o proxy.

4. Coorte é o mesmo que grupo. Por exemplo: Grupo de população geral - seguimento de uma amostra de uma população geral, isto é, de uma área bem definida geográfica ou administrativamente. No caso deste estudo (Andrade \& Lisboa, 2000), são grupos de indivíduos por faixa etária. O ciclo de cada coorte é de aproximadamente 25 anos.

5. Efeito Inércia, numa perspectiva da Escolha Racional, diz respeito ao cometimento do crime apenas quando o benefício supera o ônus da ação, ou seja, quando o valor utilitário da atividade criminosa excede a utilidade que o indivíduo poderia obter com uma atividade legal. Quando o valor utilitário do crime é inferior, o agente calcula que a melhor ação é não agir (Santos, 2009:171).

6. A justificativa para esta variável está no fato de que a interação entre potenciais criminosos com os grupos criminosos facilitaria o acesso dos primeiros ao mercado da criminalidade.

7. As variáveis macroeconômicas.

8. Coincidindo, de certa forma, com nossas conclusões em relação ao Nordeste.

9. As regiões Nordeste e Sudeste são as mais violentas, com destaque para a primeira que, nos três últimos anos da série histórica aqui avaliada, supera a segunda em taxas por 100 mil habitantes.

10. As mortes por agressão são computadas por residência e não por local de ocorrência, o que pode enviesar os dados.

11. Relevar que o tipo brasileiro é mestiço, ou seja, pardo. Com isto afirmo que não há problema racial entre as mortes violentas letais e intencionais no Brasil.

12. O gráfico inicia-se em 1999, porque em anos anteriores estão ausentes dados para as variáveis anos de escolaridade de 1 a 3 anos, de 4 a 7 anos e de 8 a 11 anos. De 1999 em diante, os dados vêm melhorando, apesar de existir ainda grande quantitativo de dados ignorados de homicídios em relação aos anos de escolaridade. Por exemplo, dos 4.556 assassinatos ocorridos em 2007, 2.212 não tinham sido catalogados pela variável anos de escolaridade.

13. Sistema de informações criminais da Polícia Civil. Secretaria de Defesa Social de Pernambuco. 
14. Em 2006 foram 4.638 mortes por homicídio, com uma taxa de 54,5 hpcmh. Em 2007, foram 4.592 mortes, com taxa de 53,5 por 100 mil. Em 2008 foram 4.525 homicídios, com uma taxa de 52 (números absolutos da Secretaria de Defesa Social do estado de Pernambuco e dos dados populacionais estimados pelo IBGE).

15. Importante destacar que uma queda na RM tem maior impacto nas reduções de violência homicida como um todo (Kahn \& Zanetic, 2009).

16. Crime Violento Letal e Intencional.

17. Mata Sul abrange os municípios de Água Preta, Amaraji, Barreiros, Belém de Maria, Catende, Chã Grande, Cortês, Escada, Gameleira, Jaqueira, Joaquim Nabuco, Maraial, Palmares, Pombos, Primavera, Quipapá, Ribeirão, Rio Formoso, São Benedito do Sul, Sirinhaém, São José da Coroa Grande, Tamandaré, Vitória de Santo Antão e Xexéu.

18. A média das taxas de homicídios por 100 mil habitantes em Ribeirão é de 52,3, numa série histórica de mais de dez anos (1996 a 2008). O ano de pico é 2008, com uma taxa de 68 hpcmh (dados preliminares do SIM: 2008).

19. Jornal do Commercio, 2009a, Cidades, p. 1.

20. Fazem parte dessa região: Agrestina, Alagoinha, Altinho, Barra de Guabiraba, Belo Jardim, Bezerros, Brejo da Madre de Deus, Cachoeirinha, Camocim de São Félix, Caruaru, Cupira, Gravatá, Jataúba, Lagoa dos Gatos, Panelas, Pesqueira, Poção, Riacho das Almas, Sairé, Sanharó, São Bento do Uma, São Caetano, São Joaquim do Monte e Tacaimbó.

21. Agreste Meridional: Águas Belas, Angelim, Bom Conselho, Brejão, Buíque, Caetés, Calçado, Canhotinho, Capoeiras, Correntes, Garanhuns, Iati, Itaíba, Jucati, Jupi, Jurema, Lagoa do Ouro, Lajedo, Palmeirinha, Paranatama, Pedra, Saloá, São João, Terezinha, Tupanatinga e Venturosa.

22. Agreste Setentrional: Bom Jardim, Casinhas, Cumaru, Feira Nova, Frei Miguelinho, João Alfredo, Limoeiro, Machados, Orobó, Passira, Salgadinho, Santa Cruz do Capibaribe, Santa Maria do Cambucá, São Vicente Férrer, Surubim, Taquaritinga do Norte, Toritama, Vertente do Lério e Vertentes.

23. Fazem parte do Sertão Central: Cedro, Mirandiba, Parnamirim, Salgueiro, São José do Belmonte, Serrita, Terra Nova e Verdejante.

24. O polígono da maconha é conhecido como região de intensa produção de maconha, composto por 14 municípios: Belém do São Francisco, Cabrobó, Carnaubeira da Penha, Floresta, Ibimirim, Lagoa Grande, Orocó, Petrolina, Salgueiro, Santa Maria da Boa Vista, Petrolândia, Itacuruba, Tacaratu e Mirandiba (Oliveira, 2006).

25. Jornal do Commercio, 2009b, Capa Dois, Recife.

26. O Sertão de Pernambuco apresenta impacto no crime organizado. Em junho de 2009, uma operação das polícias civil e militar do estado de Pernambuco resultou na prisão do prefeito da cidade de Exu, Sertão do Araripe, envolvido em acusações de facilitação de tráfico de drogas (Jornal do Commercio, 30/06/2009c).

27. Jornal do Commercio, 2009d, Cidades, p. 2. 
28. Dados fornecidos pelo Banco de dados sobre criminalidade, autorias de homicídios, prisões e apreensão de armas de fogo do Batalhão da Polícia Militar do Sertão em 2008.

29. A honra é vista como um "valor" importante para o sertanejo. Machado (2009) mostrou em matéria jornalística o impacto da honra no sertão pernambucano. Contudo, “medir” variáveis culturais ainda é um grande desafio para as ciências sociais.

30. Sertão de Itaparica: Belém do São Francisco, Carnaubeira da Penha, Floresta, Itacuruba, Jatobá, Petrolândia e Tacaratu.

31. Araripina, Bodocó, Exu, Granito, Ipubi, Moreilândia, Ouricuri, Santa Cruz, Santa Filomena e Trindade.

32. Compreende as cidades de Arcoverde, Betânia, Custódia, Ibimirim, Inajá, Manari e Sertânia.

33. Compreende Afogados da Ingazeira, Brejinho, Calumbi, Carnaíba, Flores, Iguaracy, Ingazeira, Itapetim, Quixaba, Santa Cruz da Baixa Verde, Santa Terezinha, São José do Egito, Serra Talhada, Solidão, Tabira, Triunfo e Tuparetama.

34. Petrolina vem conseguindo reduzir seus indicadores de homicídios de forma significativa. De janeiro a junho de 2009, houve 35\% de redução nos números de homicídio em relação ao mesmo período de 2008. A causa atribuída a isto está atrelada às políticas públicas de segurança (Albuquerque, 2009).

35. Grupo de Extermínio e milicianos que faziam (fazem) uma série de ilicitudes (inclusive assassinatos) em troca de "segurança" no bairro de Jardim São Paulo, no Grande Recife, onde há uma das mais altas taxas de homicídios desta cidade.

36. Em 2005 com 4.329 homicídios, em 2006 com 4.470, em 2007 com 4.556, e em 2008 com 4.345 mortes por agressão (SIM/DATASUS, 2010). 


\section{Referências bibliográficas}

ALBUQUERQUE, Roseanne. 2009. "Petrolina consegue reduzir 35,5\% o número de homicídios”. Jornal do Commercio. Disponível em: http: / /www.pebodycount. com.br/post/comentarios.php?post $=1079$.

ANDRADE, M.V.E. \& LISBOA, M.B. 2000. "Desesperança de Vida: Homicídio em Minas Gerais, Rio de Janeiro e São Paulo - 1981 a 1997”. In: R. Henriques (org.). Desigualdade e Pobreza no Brasil. Rio de Janeiro: IPEA.

BARATA, R.B. \& RIBEIRO, M.C.S.A. 2000. "Relação entre homicídios e indicadores econômicos em São Paulo, Brasil, 1996”. Rev Panam Salud Publica, 7:118-24.

BARROS, Ricardo P. de; FOGUEL, Miguel N. \& ULYSSEA, Gabriel. 2006. Desigualdade de Renda no Brasil: uma análise da queda recente. Instituto de Pesquisa Econômica Aplicada - IPEA. Vol. 1. Disponível em: www.ipea.gov.br.

BEATO FILHO, C.C. 1998. "Determinantes da criminalidade em Minas Gerais". Revista Brasileira de Ciências Sociais, 13:74-87.

\& REIS, I.A. 2000. "Desigualdade, Desenvolvimento Socioeconômico e Crime”. In: R. Henriques (org.). Desigualdade e Pobreza no Brasil. Rio de Janeiro: IPEA.

BECKER, G. 1968. "Crime and Punishment: An Economic Approach". Journal of Political Economy, v. 76:169-217.

CARVALHO, Alexandre X.; CERQUEIRA, Daniel R.C.; RODRIGUES, Rute L. \& LOBÃO, Waldir. 2007. Custos das Mortes por Causas Externas no Brasil. Instituto de Pesquisa Econômica Aplicada - IPEA, Texto para discussão $n^{\circ}$ 1268. Disponível em: www.ipea.gov.br.

CERQUEIRA, Daniel R.C. 2003. “A quem interessa a Segurança Pública no Brasil?”. In: Jorge Zaverucha; Adriano Oliveira \& Armando Nascimento (orgs.). Insegurança Pública e a Ordem Social. Recife: Ed. UFPE.

\& LOBÃO, W.A.J.L. 2003. "Condicionantes Sociais, Poder de Polícia e o Setor de Produção Criminal”. Instituto de Pesquisa Econômica Aplicada - IPEA, Texto para Discussão n ${ }^{\circ}$ 957.

2004. "Determinantes da Criminalidade: Arcabouços Teóricos e Resultados Empíricos”. Dados - Revista de Ciências Sociais, v. 47, n. 2:233-269.

CERQUEIRA, Daniel R.C.; CARVALHO, Alexandre X.Y.; LOBÃO, Waldir A.J.L. \& RODRIGUES, Rute I. 2007. Análise dos Custos e Consequências da Violência no Brasil. Instituto de Pesquisa Econômica Aplicada - IPEA, Texto para discussão $n^{\circ} 1284$. Disponível em: www.ipea.gov.br. 
DEPEN/INFOPEN. 2008. Departamento Penitenciário Nacional. Sistema de Informação Penitenciária - InfoPen. Dados Consolidados. Ministério da Justiça.

HOFFMANN, Rodolfo. 2006. "Queda da Desigualdade da Distribuição de Renda no Brasil, de 1995 a 2005 e Delimitação dos Relativamente Ricos em 2005”. In: Barros et al. (orgs.). Desigualdade de Renda no Brasil: uma análise da queda recente. Instituto de Pesquisa Econômica Aplicada - IPEA. Vol. 1.

IBGE. 2003. Síntese de Indicadores Sociais. Estudos \& Pesquisas. Informação Demográfica e Socioeconômica.

JORNAL DO COMMERCIO. 2009a. "Pasta base de cocaína apreendida em Salgueiro". Capa Dois, Recife, 5/07/2009.

. 2009b. "Prefeito de Exu é detido com armas". Capa Dois, Recife, 30/06/2009.

. 2009c. “Apreensão recorde de crack". Cidades, Recife, 20/10/2009.

. 2009d. "PF destruiu 1,6 milhão de pés de maconha este ano". Cidades, Recife, p.

2, 31/10/2009.

KAHN, Tulio \& ZANETIC, André. 2009. “O papel dos municípios na segurança pública”. Coleção Segurança com Cidadania, ano 1, n. 1. Subsídios para Construção de um Novo Fazer Segurança Pública. ISSN 1984-7025.

LESTER, D. 1996. "Suicide, homicide and the quality of life in various countries". Acta Psychiatrica Scandinavica, p. 332-34.

MACHADO, Eduardo. 2008. "A Metrópole Contra-Ataca”. Jornal do Commercio, Especial, Recife, $12 / 05 / 2008$.

. 2009. “Cabeça de Matador”. Jornal do Commercio, Especial, Recife, 13/09/2009.

MENDONÇA, M.J. 2000. Um Modelo de Criminalidade para o Caso Brasileiro. IPEA. Manuscrito.

- 2010. Os Homicídios no Brasil, no Nordeste e em Pernambuco: dinâmica, relações de causalidade e políticas públicas. Tese de Doutorado, Programa de Pós-Graduação em Ciência Política, UFPE, Recife. 271 p.

NÓBREGA JúNIOR, José Maria P. da. 2009. "Homicídios em Pernambuco: dinâmica e relações de causalidade". Coleção Segurança com Cidadania, ano 1, n. 3. Homicídios: Políticas de Controle e Prevenção no Brasil. ISSN 1984-7025.

NÓBREGA JÚNIOR, José Maria P. da; ZAVERUCHA, Jorge \& ROCHA, Enivaldo C. da. 2009. "Homicídios no Brasil: revisando a bibliografia nacional e seus resultados empíricos". Revista Brasileira de Informação Bibliográfica em Ciências Sociais - BIB, n. 67:75-94. ISSN 15168085 . 
OLIVEIRA, Adriano. 2007. Tráfico de Drogas e Crime Organizado. Peças e Mecanismos. Curitiba: Juruá Editora.

PEZZIN, L. 1986. Criminalidade Urbana e Crise Econômica. São Paulo: IPE/USP.

SANTOS, Carlos Eduardo. 2009. "Quadrilha caçada em outros estados”. Jornal do Commercio, Cidades, p. 2, 16/10/2009.

SANTOS, Marcelus J. 2009. "Dinâmica Temporal da Criminalidade: Mais Evidências Sobre o Efeito Inércia nas Taxas de Crimes Letais nos Estados Brasileiros”. Revista Economia, Brasília, v. 10, n. 1:169-194, jan./abr.

SIM/DATASUS. 2008. Dados de Mortes por Agressão do Banco de Dados do Subsistema de Informações sobre Mortalidade do Sistema Único de Saúde do Ministério da Saúde, Brasil.

SOARES, Gláucio A.D. 2008. Não Matarás. Desenvolvimento, Desigualdade e Homicídios. Rio de Janeiro: Ed. FGV.

ZAluAR, A. 1985. A Máquina e a Revolta. As Organizações Populares e o Significado da Pobreza. São Paulo: Editora Brasiliense. 


\section{Resumo}

A violência homicida é crescente no Nordeste. De 1996 a 2008 o impacto percentual foi na ordem de 106\% nos números absolutos, num crescimento linear na série histórica. O Nordeste é conhecido pela desigualdade e pela pobreza. O objetivo central deste trabalho é avaliar o grau de relação da desigualdade e da pobreza com a violência homicida. Os dados utilizados foram resgatados do Sistema de Informação de Mortalidade (SIM/SUS) e do IBGE/IPEADATA. No confronto dos dados de homicídios com as macrovariatas socioeconômicas utilizadas como proxy para desigualdade e pobreza, concluímos que não há relação entre as variáveis, ou seja, refutamos que, no Nordeste em geral, e em Pernambuco em particular, a violência homicida seja explicada (ou causada) pela desigualdade/ pobreza.

\section{Palavras-chave}

Violência homicida, homicídios, desigualdade, pobreza e instituições coercitivas

\section{Abstract}

The murderous violence is increasing in the Northeast. From 1996 to 2008 the percentage impact was around $106 \%$ in absolute numbers, a linear increase in the series. The Nor theast is known for inequality and poverty. The main purpose of this study is to assess the degree of relationship of inequality and poverty with homicidal violence. The data used were rescued from the Information System (SIM / SUS) and IBGE / IPEADATA. In the comparison of data with the homicide macrovariatas used as a proxy for socioeconomic inequality and poverty, we conclude that there is no relationship between variables. That is, we refute that in the Northeast in general and in Pernambuco, in particular, homicidal violence is explained (or caused) by the inequality / poverty.

\section{Key words}

Homicidal violence, killings, inequality, poverty and coercive institutions 